\title{
Tectonics
}

\author{
RESEARCH ARTICLE \\ 10.1029/2020TC006140 \\ Key Points: \\ - Evidence for a channel of positive \\ radial anisotropy with peak \\ magnitude at depths of $\sim 8-20 \mathrm{~km}$ is \\ found throughout the study area \\ - Absence of locally distinctive deep \\ crustal $\mathrm{V}_{\mathrm{S}}$ beneath core complexes \\ suggests overprinting by middle \\ Miocene regional ductile extension \\ - Diminished anisotropy in the hotter \\ lowermost crust may result from \\ decreased mica abundance and a \\ transition to more distributed strain
}

Supporting Information:

- Supporting Information S1

Correspondence to:

J. Wilgus,

jwilgus@unm.edu

Citation:

Wilgus, J., Jiang, C., \& Schmandt, B. (2020). A middle crustal channel of radial anisotropy beneath the northeastern Basin and Range. Tectonics, 39, e2020TC006140. https:// doi.org/10.1029/2020TC006140

Received 20 FEB 2020

Accepted 11 MAY 2020

Accepted article online 19 MAY 2020

Corrected 17 AUG 2020

This article was corrected on 17 AUG 2020. See the end of the full text for details.

2020. American Geophysical Union. All Rights Reserved.

\section{A Middle Crustal Channel of Radial Anisotropy Beneath the Northeastern Basin and Range}

\author{
Justin Wilgus $^{1}\left(\mathbb{D}\right.$, Chengxin Jiang ${ }^{1,2} \mathbb{D}$, and Brandon Schmandt ${ }^{1}$ \\ ${ }^{1}$ Department of Earth and Planetary Sciences, University of New Mexico, Albuquerque, NM, USA, ${ }^{2}$ Now at Research \\ School of Earth Sciences, The Australian National University, Acton, Australian Capital Territory, Australia
}

\begin{abstract}
A challenge in interpreting the origins of seismic anisotropy in deformed continental crust is that composition and rheology vary with depth. We investigated anisotropy in the northeastern Basin and Range where prior studies found prevalent depth-averaged positive radial anisotropy $\left(\mathrm{V}_{\mathrm{SH}}>\mathrm{V}_{\mathrm{SV}}\right)$. This study focuses on depth-dependence of anisotropy and potentially distinct structures beneath three metamorphic core complexes (MCCs). Rayleigh and Love wave dispersion were measured using ambient noise interferometry, and Bayesian Markov chain Monte Carlo inversions for $\mathrm{V}_{\mathrm{S}}$ structure were tested with several (an)isotropic parameterizations. Acceptable data fits with minimal introduction of anisotropy are achieved by models with anisotropy concentrated in the middle crust. The peak magnitude of anisotropy from the mean of the posterior distributions ranges from $3.5-5 \%$ and is concentrated at $8-20 \mathrm{~km}$ depth. Synthetic tests with one uniform layer of anisotropy best reproduce the regional mean results with $9 \%$ anisotropy at 6-22 km depth. Both magnitudes are plausible based on exhumed middle crustal rocks. The three MCCs exhibit 5\% higher isotropic upper crustal $\mathrm{V}_{\mathrm{S}}$, likely due to their anomalous levels of exhumation, but no distinctive (an)isotropic structures at deeper depths. Regionally pervasive middle crustal positive radial anisotropy is interpreted as a result of subhorizontal foliation of mica-bearing rocks deformed near the top of the ductile deformation regime. Decreasing mica content with depth and more broadly distributed deformation at lower stress levels may explain diminished lower crustal anisotropy. Absence of distinctive deep crustal $\mathrm{V}_{\mathrm{S}}$ beneath the MCCs suggests overprinting by ductile deformation since the middle Miocene.
\end{abstract}

Plain Language Summary The northeastern Basin and Range is an area of Earth's crust that has been dramatically stretched and thinned by tectonic forces. Seismic anisotropy, or wave speed dependence on direction, can provide useful insights into the way in which such deformation organizes crustal structure over long periods of time. We used surface waves to identify discrepancies between horizontally and vertically polarized wave speeds. Anisotropy focused in the middle crust at $\sim 8-20 \mathrm{~km}$ is found to best resolve the observed discrepancies. The results suggest that development and preservation of anisotropy is more effective in the middle crust compared to the lowermost crust. The transition with depth may be explained by increasingly high temperature in the lowermost crust that reduces the abundance of highly anisotropic mica minerals and promotes ductile flow that is distributed across larger volumes rather than localized shear zones. Additionally, we find that areas of exceptionally localized extension called metamorphic core complexes have middle to lower crustal seismic structure that is similar to the surrounding region despite their distinctive upper crustal structure. These structures formed early in the development of the Basin and Range; consequently, we suggest that subsequent ductile deformation in the middle to lower crust largely overprinted their structural legacies.

\section{Introduction}

The central to northern Basin and Range province of the western U.S. Cordillera is an area of large magnitude extensional strain, with up to $\sim 100 \%$ regional-scale crustal extension since the Eocene (Colgan \& Henry, 2009; Hamilton \& Myers, 1966; Long, 2018; McQuarrie \& Wernicke, 2005; Wernicke et al., 1988). Embedded within this region of distributed deformation are localized zones of more extreme extension and exhumation recorded in metamorphic core complexes (MCC), which expose rocks that were deformed below the brittle-ductile transition (BDT) and exhumed during the development of the Basin and Range (e.g., Crittenden et al., 1980; Platt et al., 2015; Whitney et al., 2013). Regional-scale extensional strain rate peaked in the middle Miocene (Colgan \& Henry, 2009; McQuarrie \& Wernicke, 2005). Slower but ongoing 
(a)

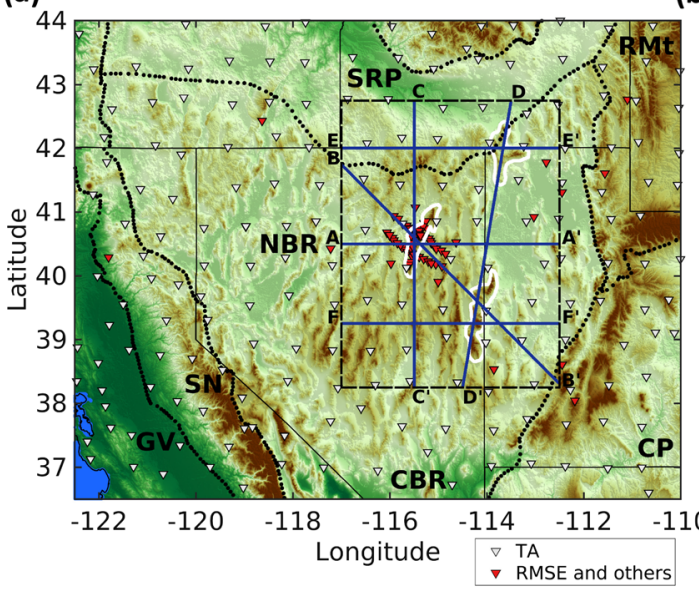

(b)

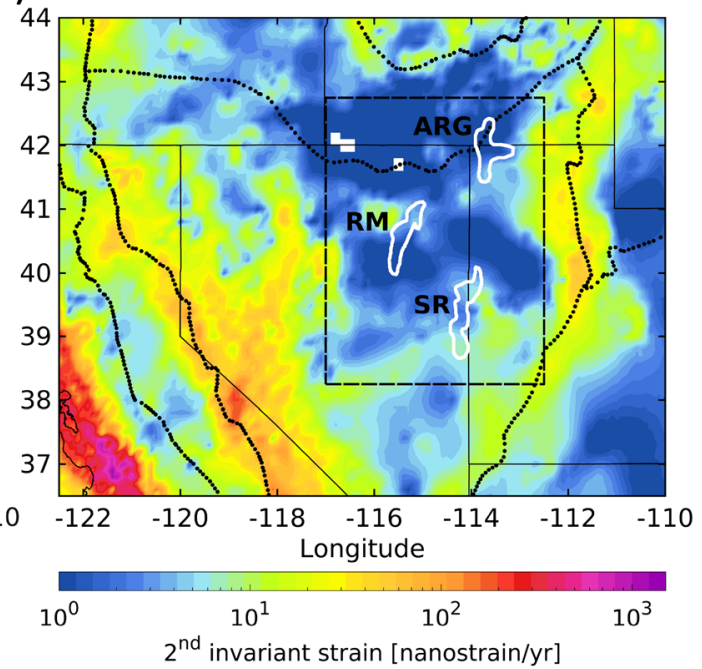

Figure 1. Maps of seismic data coverage and active regional deformation. (a) Broadband seismographs used for ambient noise cross correlations during

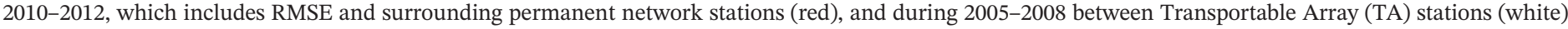

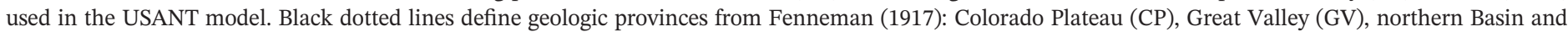

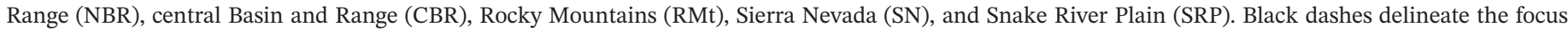

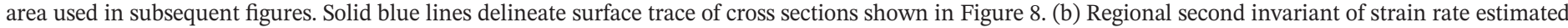

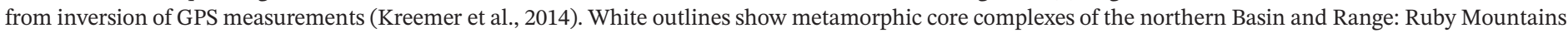
(RM), Snake Range (SR), and Albion-Raft River-Grouse Creek (ARG).

right-lateral transtensional deformation is identified by geodetic studies, with $\sim 1 \mathrm{~cm} /$ year northwestdirected relative motion between the low-strain crustal blocks of the Sierra Nevada and Colorado Plateau located on either side of the central to northern Basin and Range (Bennett et al., 2003; Hammond \& Thatcher, 2004). As a result of the well-constrained deformation over geological and contemporary timescales, the Basin and Range and its internal MCCs are useful places to study potential indicators of how subsurface strain is organized, such as seismic anisotropy.

In this study, we investigate links between deformation recorded at the surface and the development of radial seismic anisotropy in extended continental crust. We focus on the northeastern Basin and Range surrounding three MCCs: the Ruby Mountains, Snake Range, and Albion-Raft River-Grouse Creek (ARG) (Figure 1). The distribution of crustal anisotropy is a subject of expanded investigation in recent years, in part due to the development of seismic noise interferometry methods that enable extraction of short-period surface wave measurements between pairs of seismographs (e.g., Sabra et al., 2005; Shapiro \& Campillo, 2004). Interstation noise interferometry is powerful for crustal imaging with dense and large aperture seismic arrays like the Transportable Array (TA) component of EarthScope's USArray, which provides excellent geographic distributions of short-period Rayleigh and Love wave paths compared to relying on earthquakes (e.g., Lin et al., 2008). This study focuses on radial anisotropy, which makes the simplifying assumption of transverse isotropy with a vertical symmetry axis to explain inconsistencies between Rayleigh and Love wave dispersion with independent horizontally and vertically polarized $\mathrm{V}_{\mathrm{S}}$, referred to as $\mathrm{V}_{\mathrm{SH}}$ and $\mathrm{V}_{\mathrm{SV}}$ (Babuska \& Cara, 1991).

Prior investigation of radial anisotropy beneath the Basin and Range used TA data to find that positive radial anisotropy $\left(\mathrm{V}_{\mathrm{SH}}>\mathrm{V}_{\mathrm{SV}}\right)$ is prevalent in the crust and correlated with areas of extensional deformation (Moschetti et al., 2010a, 2010b). Crustal radial anisotropy has been detected in other parts of the North American Cordillera including the southern California transform margin (Wang et al., 2020), the Rio Grande rift ( $\mathrm{Fu} \& \mathrm{Li}, 2015)$, the Canadian Rockies (Dalton \& Gaherty, 2013), and Alaska (Feng \& Ritzwoller, 2019). Globally, crustal radial anisotropy has been identified in many continental areas including tectonically active and cratonic settings (Cheng et al., 2013; Dreiling et al., 2018; Duret et al., 2010; Harmon \& Rychert, 2015; Huang et al., 2010; Luo et al., 2013; Lynner et al., 2018; Ojo et al., 2017; Shapiro et al., 2004; Sherrington et al., 2004; Xie et al., 2013). The most conventional interpretation for its origin is the strain-induced alignment of anisotropic crustal minerals forming an aggregate crystallographic preferred 
orientation (CPO; Mainprice \& Nicolas, 1989; Weiss et al., 1999). However, there are plausible alternatives or additional contributions such as preferentially oriented fractures in the shallow crust, sedimentary stratigraphy, and organization of partial melt or fluids that may be prevalent in thick orogenic crust or magmatic systems (Almqvist \& Mainprice, 2017; Backus, 1962; Hacker et al., 2014; Harmon \& Rychert, 2015; Jaxybulatov et al., 2014; Wang et al., 2020; Leary et al., 1990; Lynner et al., 2018; Matharu et al., 2014). The thin crust of the modern Basin and Range makes pervasive midcrustal melting less likely compared to settings such as the Tibetan plateau, which has about double the thickness of radiogenic heat-producing crust (e.g., Hacker et al., 2014). Moschetti et al. (2010a) favor CPO as the most probable origin of radial anisotropy in the highly extended middle and lower crust of the Basin and Range, and laboratory measurements of exhumed rocks from the Basin and Range support the presence of CPO-derived anisotropy and the approximate validity of transverse isotropy (Erdman et al., 2013).

We further investigate radial anisotropy in the northeastern Basin and Range with combined analysis of Rayleigh and Love waves extracted from TA data and a denser regional array centered on the Ruby Mountains MCC (Figure 1). Prior investigations using only the TA lacked the seismograph density to identify potentially anomalous anisotropy beneath Ruby Mountains MCC and focused on establishing the necessity of regionally prevalent anisotropy by assuming a uniform distribution in the middle and lower crust (Moschetti et al., 2010a). This study evaluates whether distinctive radial anisotropy exists beneath the Ruby Mountains or other MCCs in the northeastern Basin and Range. We also evaluate depth dependence of radial anisotropy to identify how depth-dependent composition and rheology may influence development of crustal radial anisotropy.

\section{Geologic and Geodynamic Setting}

Formation of the Basin and Range as a province of extensional deformation and intraplate magmatism began in the Paleogene and closely followed cessation of Mesozoic crustal shortening that culminated with the Sevier and Laramide orogenies (Coney \& Harms, 1984). Western plate boundary reorganization including subduction of the Kula-Farallon and Pacific-Farallon ridges decreased subduction zone width and coincided with the transition from dominantly compressional to extensional deformation in the Cordilleran interior (Schellart et al., 2010). Diminished compressional stress and thick elevated continental crust gave rise to gravitational collapse in what became the Basin and Range (Coney \& Harms, 1984; Dewey, 1988; Rey et al., 2001). Postorogenic collapse began with voluminous magmatism and localized extension sweeping from north to south in the Eocene and Oligocene, while regional scale extension dominantly occurred in the middle Miocene (Best \& Christiansen, 1991; Camp et al., 2015; Colgan \& Henry, 2009; Wernicke \& Snow, 1998). Columbia River, Steens, and northern Nevada Rift basaltic volcanism ( 15-17 Ma) were approximately coeval with Miocene acceleration of extension in the northern Basin and Range, suggesting that mantle upwelling further contributed to driving extensional collapse (Camp et al., 2015; Colgan \& Henry, 2009). Continued growth of the San Andreas transform boundary since 10 Ma was accompanied by an increasing component of right-lateral shear strain and concentration of strain near the boundaries of the Basin and Range compared to its interior (Colgan \& Henry, 2009; Wernicke \& Snow, 1998). Slow contemporary strain rates (Figure 1; Bennett et al., 2003; Hammond \& Thatcher, 2004; Kreemer et al., 2014) are consistent with minor amounts of slip on extensional faults in the north-central Basin and Range from the late Miocene through the Holocene (Pérouse \& Wernicke, 2017).

Within the northern Basin and Range are three MCCs: the Ruby Mountains, Snake Range, and ARG Mountains (Figure 1). This study benefits from data collected by the recent Ruby Mountains Seismic Experiment (RMSE), which provides exceptionally dense, 5-10 km spacing, broadband seismograph coverage of the Ruby Mountains (Figure 1; Litherland \& Klemperer, 2017). The northern Ruby Mountains expose Proterozoic to Paleozoic metasedimentary rocks of the miogeocline that were intruded by Mesozoic to early Cenozoic plutons, buried during crustal shortening of the Sevier Orogeny, and then subjected to multiple phases of exhumation beginning in the late Cretaceous (Hodges et al., 1992; MacCready et al., 1997; Sullivan \& Snoke, 2007). The southern Ruby Mountains expose unmetamorphosed Paleozoic sedimentary rocks that have not been buried below their stratigraphic depths (Colgan et al., 2010). Intrusion of the Harrison Pass pluton into the transition between the southern and northern Ruby Mountains occurred at 36 Ma during an Eocene to Oligocene period of ductile shear deformation in the middle crust (Barnes 
et al., 2001; MacCready et al., 1997). Exhumation and extension in the southern Ruby Mountains were concentrated in the middle Miocene from 17-10 Ma (Colgan et al., 2010; Haines \& van der Pluijm, 2010).

The Snake Range and ARG MCCs are included in the study area, but data coverage in these regions is mainly provided by TA seismographs spaced $\sim 70 \mathrm{~km}$ apart (Figure 1; Figure S1 and Table S1 in the supporting information). The Snake Range MCC exposes Proterozoic to Cenozoic strata and records up to $450 \%$ extension of the brittle upper crust (Lee et al., 1987). Metamorphism and ductile deformation of the deeply exhumed footwall dominantly occurred from the Oligocene to early Miocene, 35-20 Ma, followed by fault-driven exhumation to within $\sim 3 \mathrm{~km}$ of the surface in the middle Miocene, 17 Ma (Gébelin et al., 2011; Miller et al., 1999). In the ARG, outcrops expose Archean to Cenozoic stratigraphic units (Compton et al., 1977), and metamorphism of gneiss domes there dominantly occurred in the Oligocene, 34-25 Ma (Egger et al., 2003; Konstantinou et al., 2013). The ARG exposes strata exhumed from $\sim 10 \mathrm{~km}$ greater depth than in the surrounding region; however, much of the exhumation was likely driven by locally pronounced thermal weakening of the crust and ascent of granitic diapirs during the Oligocene (Konstantinou et al., 2013). A later phase of fault-driven Miocene exhumation from 15-7 Ma led to the surface exposures of the ARG MCC (Egger et al., 2003; Wells et al., 2000).

Modern lithospheric structure of the northern Basin and Range is characterized by high heat flow, thin continental mantle lithosphere, and a low-relief Moho interface defining an average crustal thickness of 30-35 km (Gilbert, 2012; Hasterok \& Chapman, 2007; Klemperer et al., 1986; Lowry \& Pérez-Gussinyé, 2011; Schmandt et al., 2015; Zandt et al., 1995). Contemporary heat flow in the northern Basin and Range has an estimated median of $79 \mathrm{~mW} / \mathrm{m}^{2}$, which is consistent with steady-state thermal lithospheric thickness of $\sim 75 \mathrm{~km}$ (Hasterok \& Chapman, 2007). Teleseismic imaging with $P$ to $S$ and $S$ to $P$ converted waves indicates a sharp lithosphere-asthenosphere boundary at similar or shallower depths of $\sim 55-75 \mathrm{~km}$, and the sharpness and amplitude of the interface, along with temperature estimates from seismic tomography, suggest it may be defined by partial melt at the base of the lithosphere (Hansen et al., 2015; Lekić \& Fischer, 2014; Levander \& Miller, 2012). Controlled source seismic reflection studies show steeply dipping normal faults in the upper crust, $\lesssim 6-8 \mathrm{~km}$, transitioning to prevalent subhorizontal layering in the middle and lower crust underlain by lower reflectivity mantle lithosphere (Hauser et al., 1987; Holbrook et al., 1991; Klemperer et al., 1986; McCarthy, 1986; Stoerzel \& Smithson, 1998). Fine-scale deep crustal layering illuminated by high-frequency reflections may be due to a combination of ductile extension accommodated by localized shear zones and intrusion of mafic sills during the late Eocene through Miocene magmatic flare-up in the Basin and Range (Gans, 1987; Holbrook et al., 1991; Klemperer et al., 1986; McCarthy \& Thompson, 1988; Valasek et al., 1989). Regional ductile flow in the middle to lower crust during and after the middle Miocene phase of regional extension is likely based on the low-relief Moho surface, estimated modern Moho temperatures of $\sim 600-800^{\circ} \mathrm{C}$, and decoupling of azimuthal anisotropy in the crust and mantle (Block \& Royden, 1990; Gans, 1987; Klemperer et al., 1986; Lin et al., 2011; Schutt et al., 2018).

\section{Data and Methods}

\subsection{Data}

Continuous three-component (3-C) broadband seismic data were collected from the RMSE (Litherland \& Klemperer, 2017) and surrounding permanent network stations (Figure 1; Table S1). Using interstation measurements of surface wave propagation extracted from empirical Green's functions estimated using ambient noise interferometry, we obtain Rayleigh and Love wave data (Figure 2; Bensen et al., 2007). Prior to the RMSE, the TA, deployed from 2006-2008, provided the best broadband coverage of the study area in the northern Basin and Range with $\sim 70 \mathrm{~km}$ spacing. The RMSE deployed 50 3-C broadband seismometers $\sim 5-10 \mathrm{~km}$ apart along three transects across the Ruby Mountains between 2010 and 2012, thereby providing opportunities for improved resolution of regional crustal structure.

\subsection{Phase Velocities}

Interstation Rayleigh and Love wave dispersion measurements from two different time periods were used to invert for radially anisotropic $\mathrm{V}_{\mathrm{S}}$ structure. Rayleigh and Love wave dispersion measurements were made with the vertical (ZZ) and transverse (TT) noise cross-correlation functions, respectively (Figure 2). Interstation dispersion measurements from Ekström (2017) were used for the TA time period 2005-2008. 

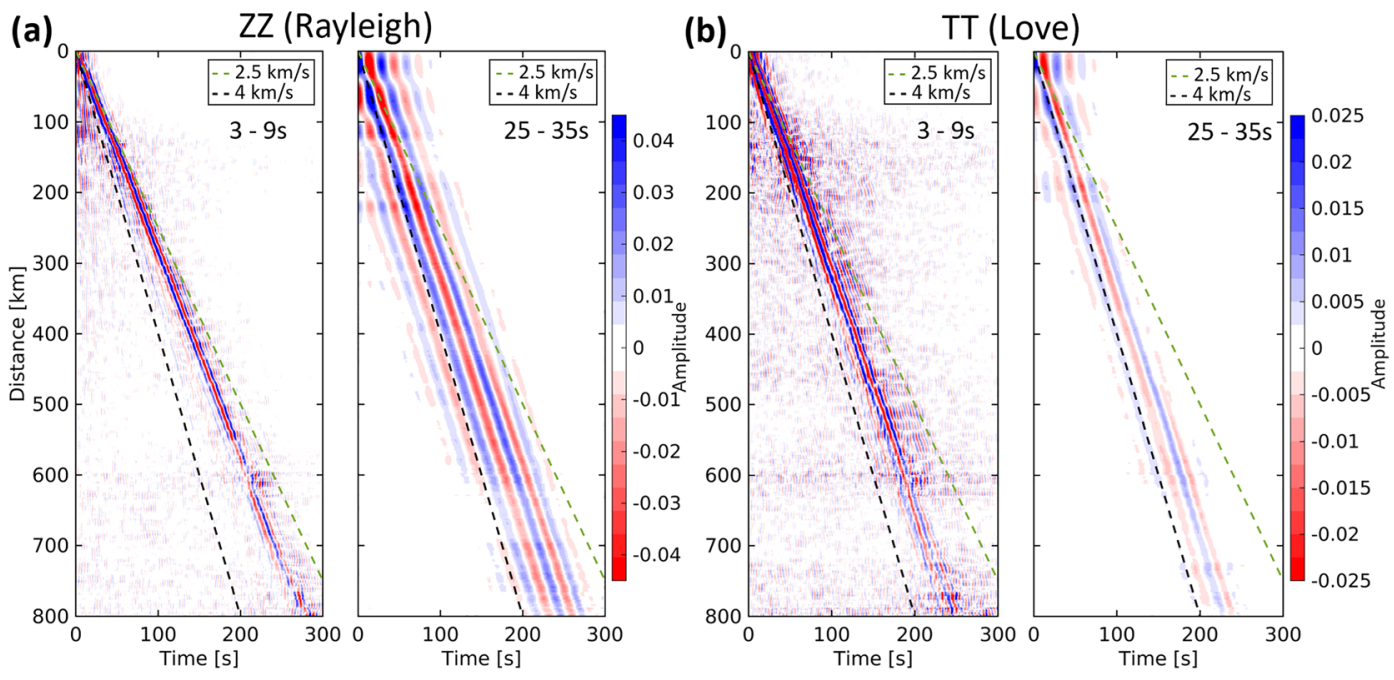

Figure 2. Stacked noise correlations from the RMSE and regional seismographs. (a) Stacked time versus distance image of 3,260 vertical component (ZZ) interstation noise cross correlations recorded over 18 months for the RMSE and exterior stations (red triangles in Figure 1). Correlations bandpass filtered between 3-9 s and 25-35 s periods are shown in the left and right panels, respectively. Longer periods propagate at higher velocities as expected for dispersive Rayleigh waves. (b) Same as panel (a), but TT component correlations are plotted to show Love waves.

New noise cross-correlation functions were calculated for the RMSE deployment from 2010-2012 (Figure 2). To better merge the RMSE and TA time period measurements, interstation noise cross-correlation functions were calculated for the RMSE and a set of 26 azimuthally distributed permanent seismographs operating between 2010 and 2012 (Figures 1 and S1). We followed Bensen et al. (2007) to process the new noise cross-correlation measurements, with the slight modification of using half-overlapping 4-hr, rather than daily, time windows (e.g., Seats et al., 2012). Rayleigh and Love wave phase velocities were estimated at 5-30 s periods using frequency-time analysis (Bensen et al., 2007; Lin et al., 2008). Phase velocities from Ekström (2017) were calculated using Aki's spectral formulation (Ekström et al., 2009), which produces results that are consistent with frequency-time analysis (Tsai \& Moschetti, 2010). Three types of quality control were applied to the new dispersion measurements to ensure that Rayleigh or Love wave signal-tonoise ratio is $>6$, phase velocity is between 2 and $5 \mathrm{~km} / \mathrm{s}$, and the interstation distance is $>2$ wavelengths. Interstation phase velocities were inverted for phase velocity maps for periods at 5-30 s for Rayleigh waves and 6-30 s for Love waves using a damped least-squares inversion and great circle ray paths following Ekström (2017). RMSE measurements with misfits beyond two standard deviations were removed, and the inversion was repeated once more (Figure S2).

\subsection{Anisotropic $\mathrm{V}_{\mathrm{S}}$ Inversion}

Models of $\mathrm{V}_{\mathrm{S}}$ structure as a function of depth were estimated at each geographic location using a Bayesian Markov chain Monte Carlo (BMMC) inversion (Shen et al., 2013). Each $\mathrm{V}_{\mathrm{S}}$ model is parameterized by a set of spline functions in the crust and a single layer in the upper mantle, and the number of splines in the crust and the assumption of isotropy or radial anisotropy were varied in different inversion cases described below (Figures 3 and S3). Uniform prior distributions were assumed for the values of the spline coefficients. The range of $\mathrm{V}_{\mathrm{S}}$ models permitted by the prior distribution is shown in Figure 3. Forward calculations of Rayleigh and Love dispersion curves were performed using the Computer Programs in Seismology software package (Herrmann, 2013). $\mathrm{V}_{\mathrm{P}}$ and density needed for forward modeling were derived from the empirical scaling relationships of Brocher (2005) for the crust. In the upper mantle, we use relative scalings from Panning and Romanowicz (2006) based on the Preliminary reference Earth model (PREM) (Dziewonski \& Anderson, 1981). Goodness of fit between predicted and observed dispersion curves was calculated with a standard chi-squared $\left(\chi^{2}\right)$ misfit, $\chi^{2}=\sum\left((\text { obs }- \text { pred })^{2} / \sigma^{2}\right)$, using phase velocity uncertainties, $\sigma$, (Table S2) from Jiang et al. (2018). Each 1-D inversion was run for 1.5 million iterations, and model selection is guided by the Metropolis-Hastings algorithm (Hastings, 1970; Mosegaard \& Tarantola, 1995). Because the $\chi^{2}$ values of the best models vary spatially within the study area, the best 800 models are chosen to 
(a)

(b)

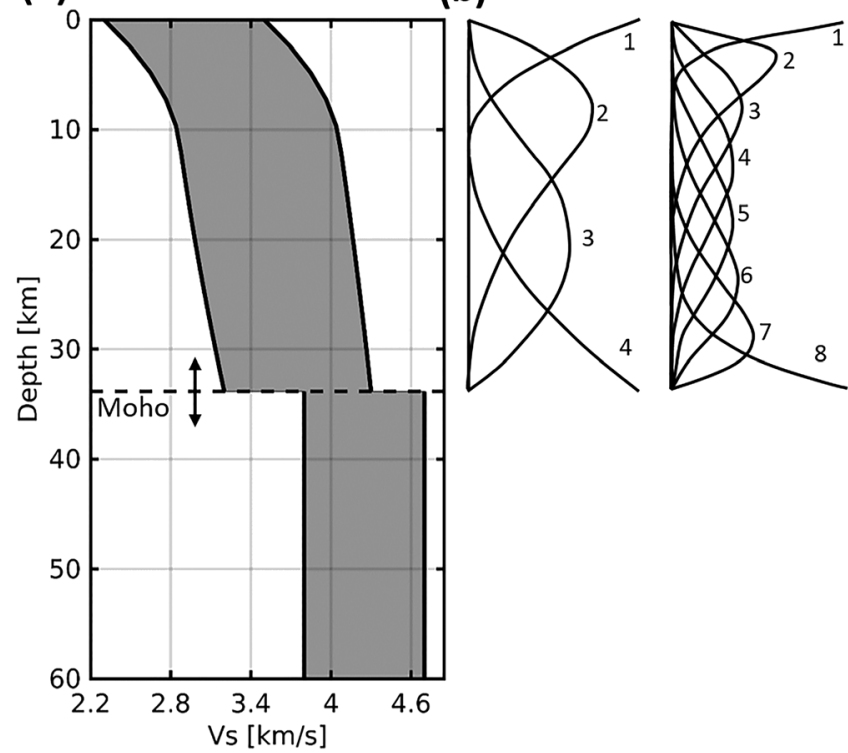

Figure 3. Prior model space range and $b$-spline parameterization of crustal $V_{S}$. (a) The range of $V_{S}$ spanned by the prior distribution is shaded in the gray corridor. The example is shown with the regional mean Moho depth.

(b) Parameterizations with four or eight $b$-splines, which allow smoothly varying crustal $V_{S}$ with a modest number of parameters compared to using discrete layers. In the different parameterization cases described in section 3.3, some, all, or none of the b-splines in the crust are allowed to be radially anisotropic.

represent the posterior distribution. The mean of the posterior distribution at each geographic point is shown as the final result on a regular $0.25^{\circ}$ grid.

To validate the necessity of seismic anisotropy in the crust and test the depth-dependence of radial anisotropy, we constructed five different BMMC inversion parameterizations (Figure 4). The five cases are (1) isotropic crust (four splines) and mantle; (2) isotropic crust (four splines), anisotropic mantle; (3) isotropic crust (eight splines), anisotropic mantle; (4) anisotropic crust (four splines), anisotropic mantle; and (5) anisotropic middle crust (middle two of four splines), anisotropic mantle (Figures 3 and 4). In each case, the upper mantle layer extends to $100 \mathrm{~km}$ depth. PREM $\mathrm{V}_{\mathrm{P}} / \mathrm{V}_{\mathrm{S}}$ and density are assumed at depths greater than the local Moho. Given the maximum period of $30 \mathrm{~s}$ used in this study, there is negligible sensitivity to structure at $>100 \mathrm{~km}$ depth. $\mathrm{V}_{\mathrm{SH}}$ and $\mathrm{V}_{\mathrm{SV}}$ are independent in inversion cases that consider anisotropy. The resulting isotropic $\mathrm{V}_{\mathrm{S}}$ models were estimated using Voigt averaging, $\mathrm{V}_{\mathrm{S}}=\sqrt{ }\left(\left(2 \mathrm{~V}_{\mathrm{SV}}{ }^{2}+\mathrm{V}_{\mathrm{SH}}{ }^{2}\right) / 3\right)$, and radial anisotropy was calculated post-inversion, where radial anisotropy $=100\left(\mathrm{~V}_{\mathrm{SH}}-\mathrm{V}_{\mathrm{SV}}\right) / \mathrm{V}_{\mathrm{S}}$.

Each of the five inversion parameterization cases were run using three different regional crustal thickness models (Figure 5; Buehler \& Shearer, 2017; Schmandt et al., 2015; Shen \& Ritzwoller, 2016) and an interpreted local crustal thickness model calculated below each station within the RMSE (Figure 5; Litherland \& Klemperer, 2017). The motivation for testing the different crustal thickness models is to determine if the strength and pattern of radial anisotropy are dependent on the choice of crust thickness model. Only subtle variations were found in the radially anisotropic structure as a result of different crustal thickness models (Figures 5, S4, and S5). So, we primarily present results using the crust thickness model of Schmandt et al. (2015) which contains measurements from both RMSE and TA data.

\section{Results}

\subsection{Regional Mean Misfit and Radial Anisotropy}

The five model parameterization cases provide insight into the importance of crustal radial anisotropy and its depth dependence. Assuming isotropy in the crust (Cases 1-3) results in large regional mean $\chi^{2}$ misfits of 4-7 (Figure 4). Compared to the fully isotropic crust and mantle in Case 1, parametrization allowing upper mantle radial anisotropy (Case 2) reduces the regional mean $\chi^{2}$ misfit from 7.3 to 5.2. Case 3 explores 

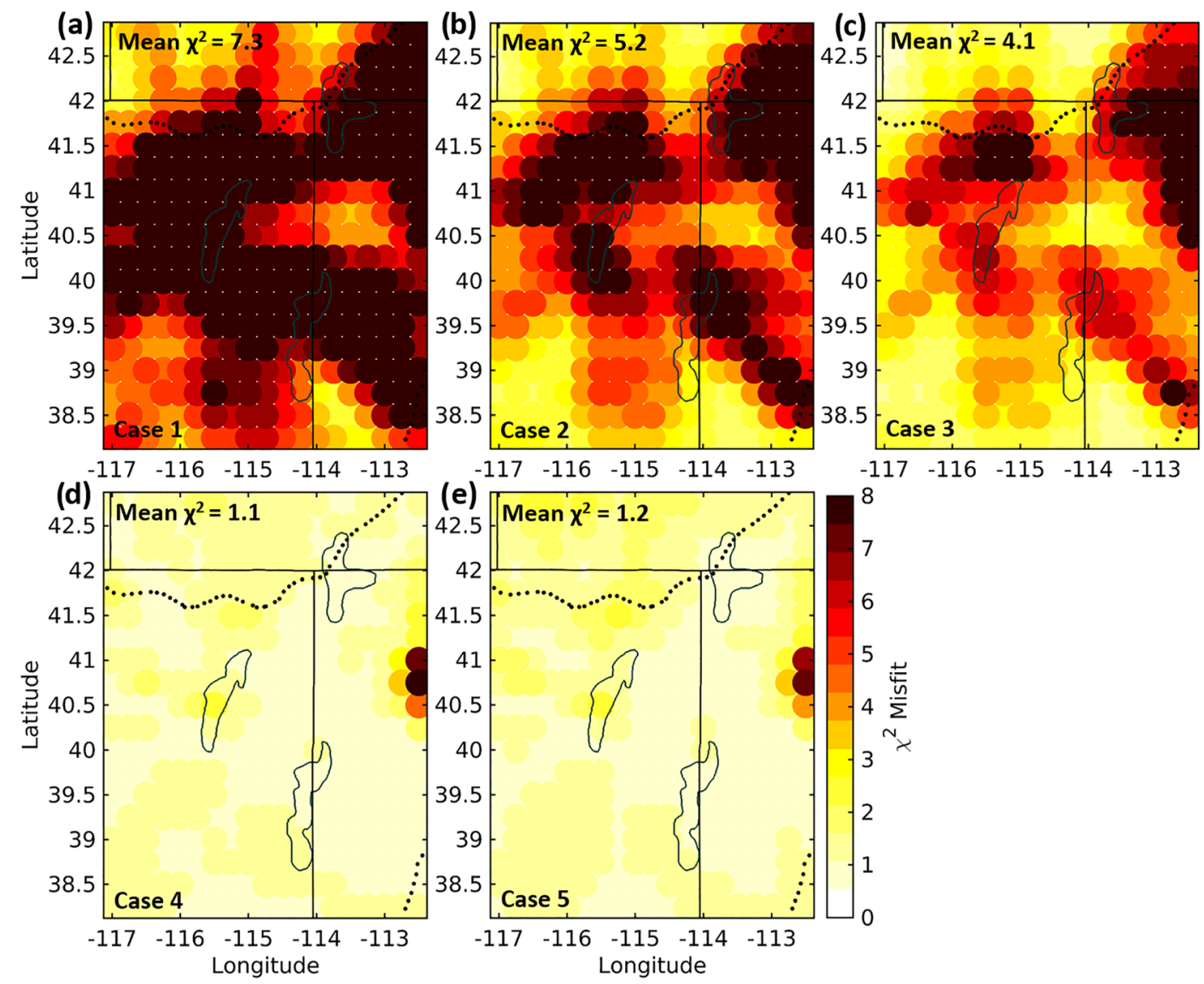

Figure 4. Data misfit maps for different inversion parameterizations. (a-e) Chi-squared $\left(\chi^{2}\right)$ misfit maps for the five parameterization cases described in section 3.3. All maps correspond to inversions using the crustal thickness model of Schmandt et al. (2015). Regional mean $\chi^{2}$ misfits are given in the upper left portion of each map. Maps in panels (a)-(c) correspond to inversions assuming isotropic $\mathrm{V}_{\mathrm{S}}$ in the crust and exhibit high $\chi^{2}$ misfits. Maps in panels (d) and (e) allow anisotropy in the entire crust and middle crust, respectively, and achieve similarly low regional mean $\chi^{2}$ misfits.

whether doubling the isotropic parameters in the crust can explain the Rayleigh-Love discrepancy without introducing crustal anisotropy. This approach with eight isotropic b-splines slightly reduces the regional mean $\chi^{2}$ misfit from 5.2 to 4.1. Introduction of radial anisotropy throughout the crust (Case 4) and anisotropy focused in the middle crust (Case 5) result in superior regional mean $\chi^{2}$ misfits of $\sim 1$ (Figures 4 and S4). Persistently high mean $\chi^{2}$ misfits located on the eastern edge of the study region are coincident with, and likely influenced by, the deep ( $\sim 3 \mathrm{~km}$ in this location) Great Salt Lake basin structure (Mikulich \& Smith, 1974).

To further evaluate the depth dependence of radial anisotropy, additional tests were performed allowing the mantle and only a single crustal b-spline to be radially anisotropic in each test. Individually introducing radial anisotropy for either b-spline 2 or 3 also achieves low regional mean $\chi^{2}$ misfits of 1.2 and 1.3, respectively (Figure 6). Higher mean misfits of 2 and 3.3 were found when radial anisotropy was only allowed for b-splines 1 and 4, respectively. In these cases of only allowing radial anisotropy for the uppermost or lowermost b-spline, larger peak amplitudes of anisotropy were required, up to $\sim 10-15 \%$. Thus, crustal radial anisotropy is necessary to adequately fit the Rayleigh and Love wave dispersion measurements, and it is possible to achieve similarly good fit to the data using only middle crustal radial anisotropy with a peak magnitude of $\sim 4-5 \%$. Prior studies show that assuming uniform radial anisotropy through the entire crust and confining it to the middle and lower crust are alternative parameterization approaches that can achieve regional mean $\chi^{2}$ misfits of $\sim 1$ (e.g., Moschetti et al., 2010a; Xie et al., 2015; Figure S6). These approaches are attractive for only requiring one anisotropic parameter; however, the tests conducted here demonstrate that just one anisotropic parameter is equally effective if it is isolated to middle crustal depths (Figures 6 and S6). 

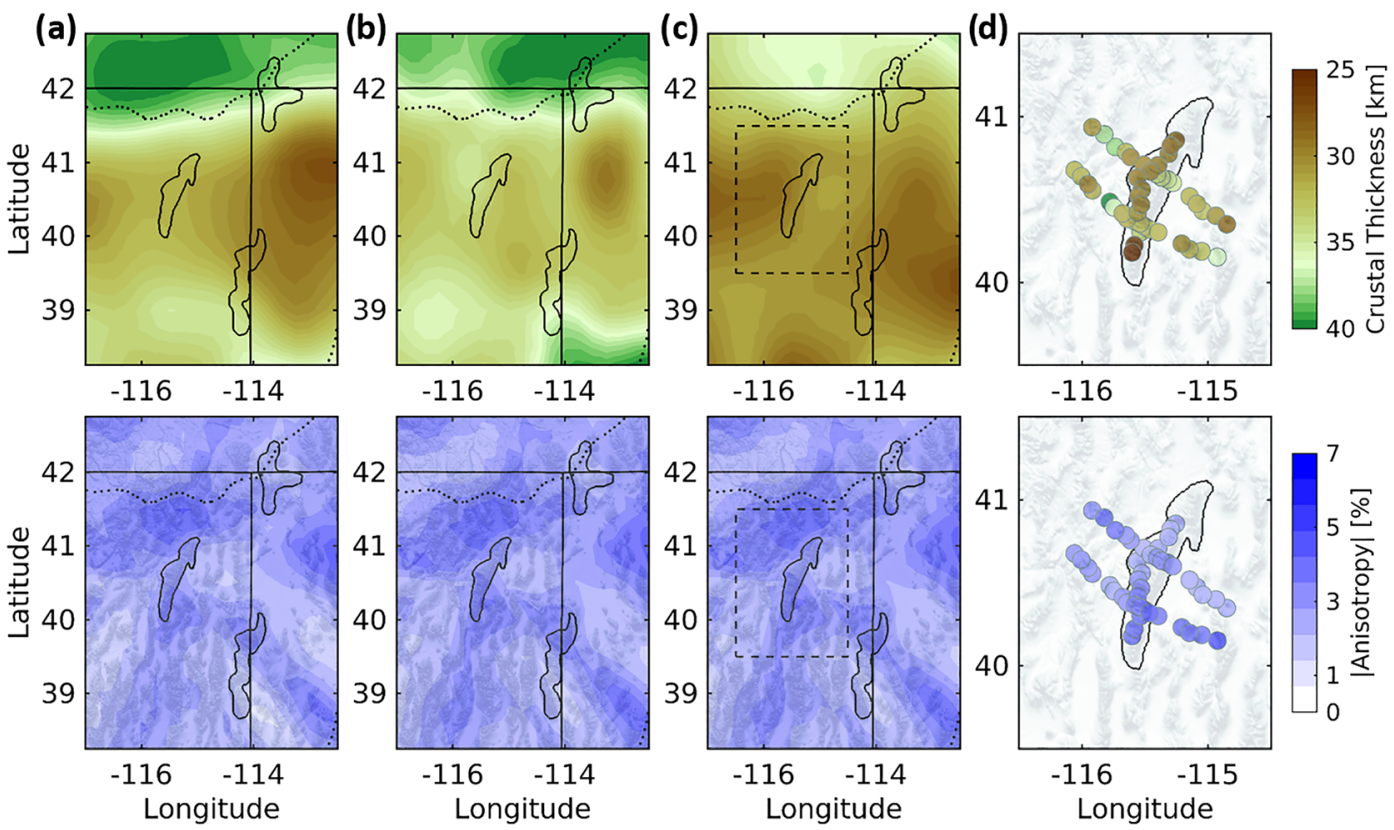

Figure 5. Effects of crust thickness models on estimates of crustal radial anisotropy. (a) The top panel shows the crust thickness model of Schmandt et al. (2015), and the bottom panel shows the depth-integrated absolute value of radial anisotropy from Inversion Case 4 in which anisotropy is allowed in all four crustal b-splines. (b, c) Similar to panel (a) but showing results using the crustal thickness models of Buehler and Shearer (2017) and (c) Shen and Ritzwoller (2016), respectively. (d) Similar to panels (a)-(c) except local crustal thickness results from Litherland and Klemperer (2017) are only available beneath stations from the RMSE array. Dashed lines in panel (c) demarcate the area shown in panel (d). Distribution and magnitude of anisotropy are similar regardless of the choice of crust thickness model.

The depth of the regional mean peak radial anisotropy varies from 8-20 km for the parameterizations tested here that achieve regional mean $\chi^{2}$ misfits of $\sim 1$. The shallowest peak depth and smallest magnitude, $8 \mathrm{~km}$ and $3.5 \%$, is found if only b-spline 2 is anisotropic. The deepest peak depth and larger magnitude, $20 \mathrm{~km}$ and $5 \%$, are found if only b-spline 3 is anisotropic. Among parameterizations allowing multiple anisotropic b-splines, the peak depth and magnitude are $11 \mathrm{~km}$ and $5 \%$, respectively, if all four b-splines are anisotropic (Case 4) and $14 \mathrm{~km}$ and 3.5\% if just b-splines 2 and 3 are anisotropic (Case 5). The larger peak magnitude that occurs when all four b-splines are anisotropic is related to the introduction of negative anisotropy in much of the regional upper crust (Spline 1) and more sporadically in the lower crust (Spline 4).

\subsection{Variations in Isotropic and Anisotropic Structure}

Considering the broad depth sensitivity of surface waves, we discuss the main results at four depth ranges: upper crust, middle crust, lower crust, and upper mantle (Figure 7). The upper crust is set to extend from $0-5 \mathrm{~km}$, where the first b-spline depth range dominates and the shortest period phase velocities in the inversion $(6 \mathrm{~s})$ have concentrated sensitivity. The depth extents of the middle and lower crust are determined by evenly splitting the remaining crust thickness. Since the major patterns in isotropic $\mathrm{V}_{\mathrm{S}}$ variations remained consistent through the different radial anisotropy parameterization cases (Figure S7), we focus on describing inversion results from Case 4 in which radial anisotropy was allowed at all crustal and upper mantle depths. The plotted results represent the mean isotropic $V_{S}$ and anisotropy of the posterior distribution from the BMMC inversions for the region. To help identify where anisotropy may not be necessary to provide a similarly good fit to the data, we also provide plots that show only areas where the absolute value of radial anisotropy has a statistical significance greater than one standard deviation of the posterior distribution (Figures 7 and 8; Figures S7 to S10). In the upper crust, negative radial anisotropy is more commonly observed than positive radial anisotropy, and in many areas, its significance exceeds one standard deviation of the posterior distribution. The prevalence of upper crustal negative radial anisotropy is consistent with some prior studies suggesting the presence of vertical to subvertical cracks at low confining pressures 

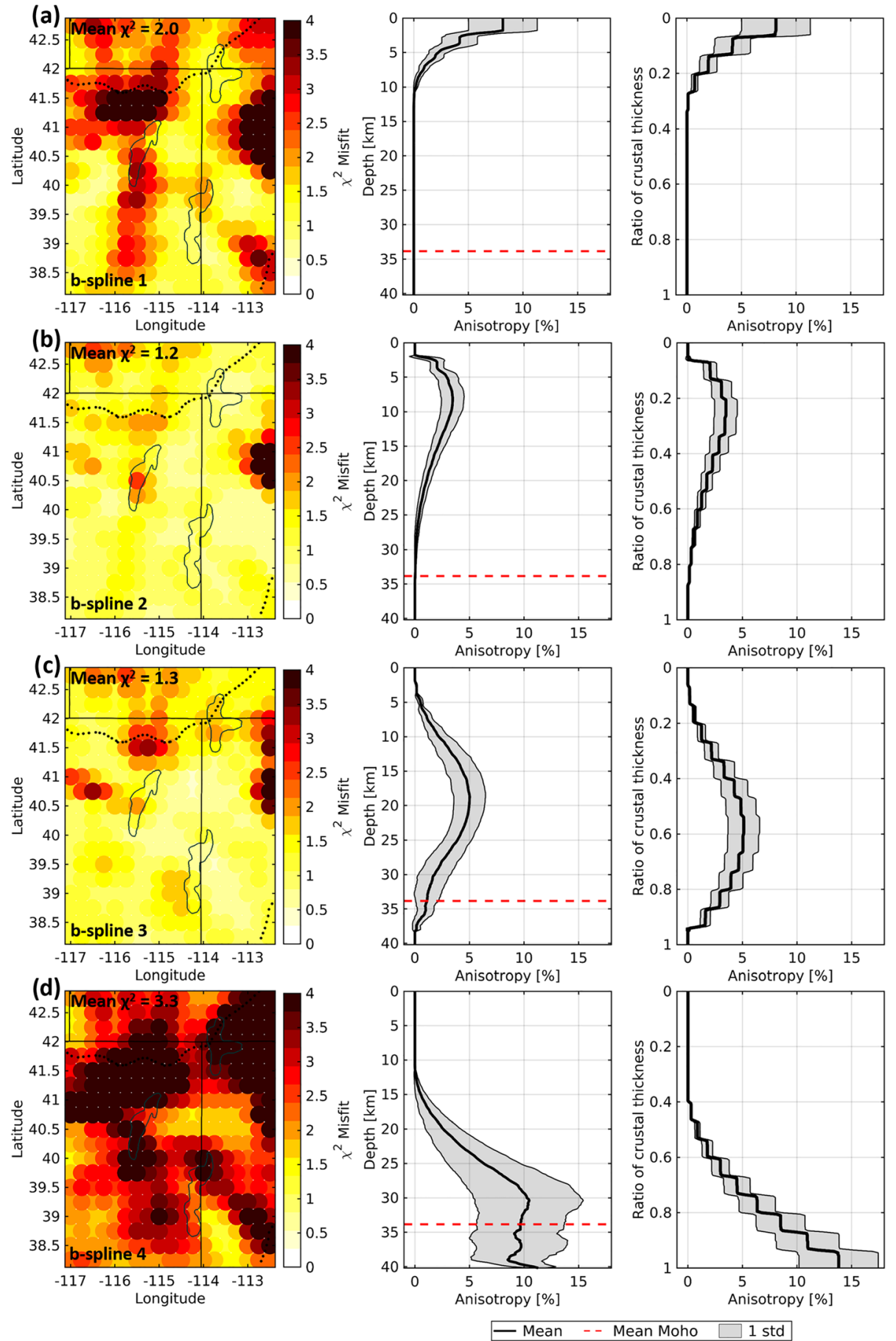

Figure 6. Misfit maps and anisotropic depth profiles for tests with anisotropy in one isolated crustal b-spline. (a) Left panel shows the regional mean $\chi^{2}$ misfit map if anisotropy is only allowed for b-spline 1 . The crustal b-spline that is allowed to be anisotropic is labeled in the lower left corner of the map, and the regional mean $\chi^{2}$ misfit is labeled in the upper left corner of the map. Middle panel shows the resulting radial anisotropy profile including the mean (black line) and one standard deviation corridor (gray) of the posterior distribution. Right panel also shows the radial anisotropy depth profile but with depth normalized to local crustal thickness. All results shown in this figure correspond to inversions assuming the regional crust thickness model of Schmandt et al. (2015). (b-d) Similar to panel (a) but showing results for tests allowing anisotropy individually in b-splines $2-4$, respectively. Note that individually allowing radial anisotropy for b-splines 2 and 3 fits the data better than for splines 1 and 4 while requiring smaller magnitudes of anisotropy. 

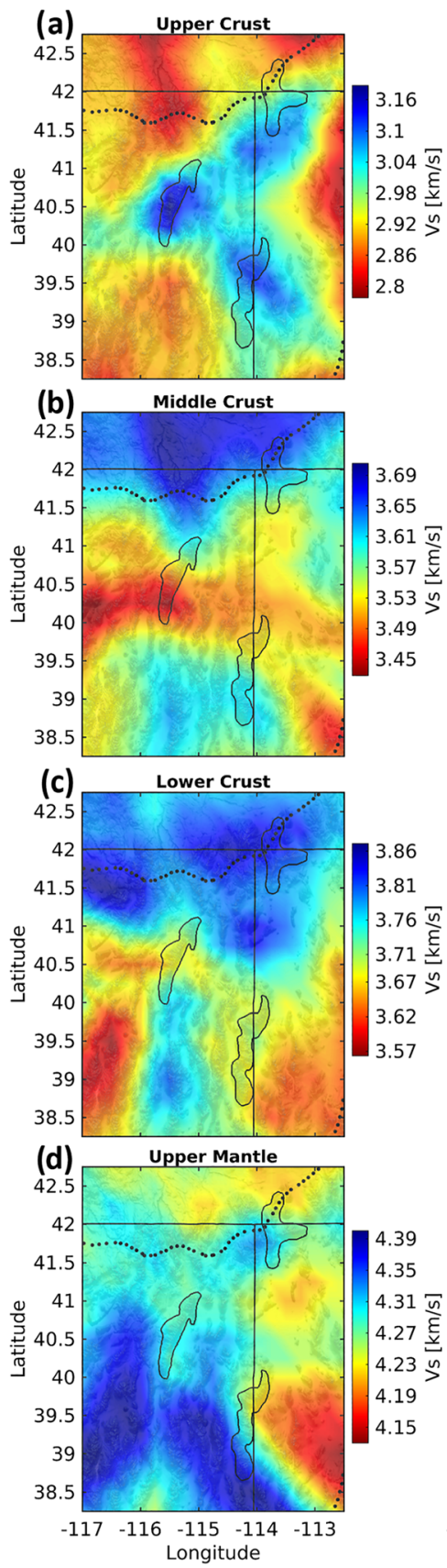

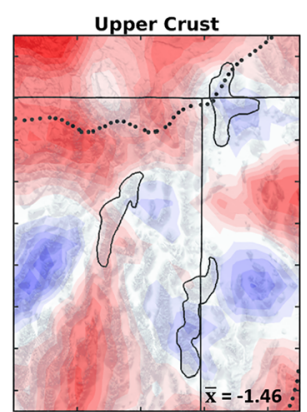

Middle Crust

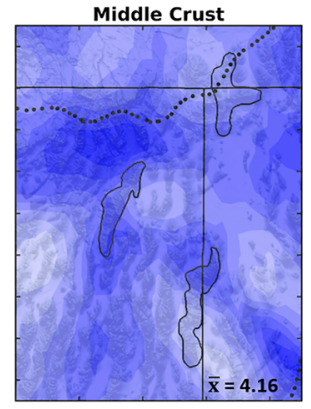

Lower Crust

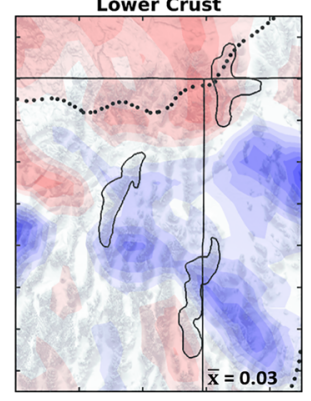

Upper Mantle

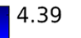

4.35

$4.31 \mathrm{n}$

4.27 है

$4.23 \mathrm{~s}$

4.19

4.15
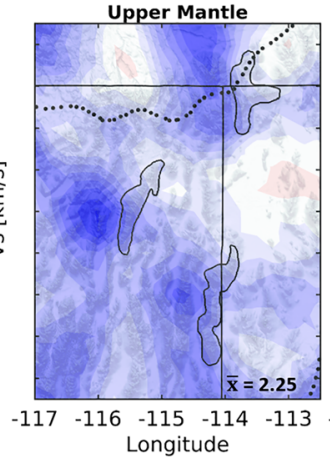

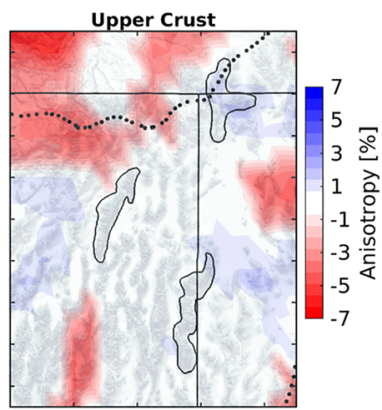

Middle Crust

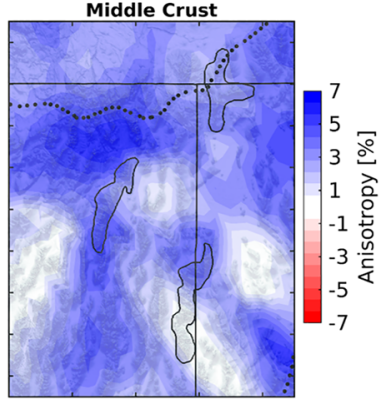

Lower Crust

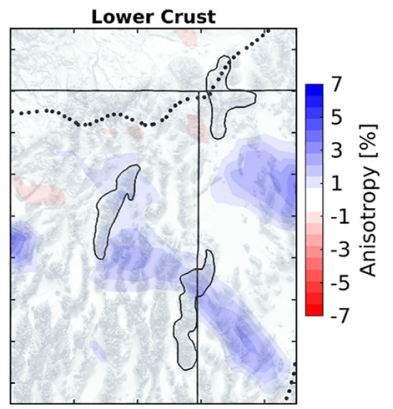

Upper Mantle

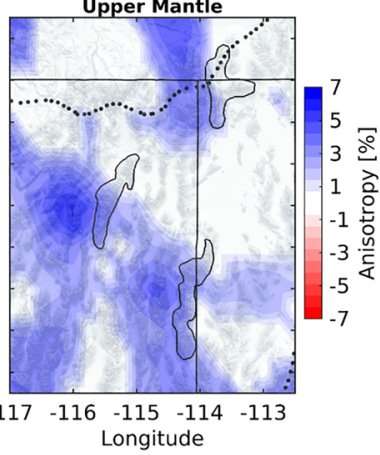

Figure 7. Depth-averaged isotropic $\mathrm{V}_{\mathrm{S}}$ and radial anisotropy maps for the upper crust, middle crust, lower crust, and upper mantle. (a) Depth-averaged isotropic $V_{S}$ and radial anisotropy of the upper crust. Left panel shows isotropic velocity. Middle panel shows radial anisotropy results. The depth-averaged mean radial anisotropy of the map area $(\overline{\boldsymbol{x}})$ is given in the lower right corner. Right panel shows only results that have an absolute value of radial anisotropy with a statistical significance greater than one standard deviation of the posterior distribution. The upper crust maps average results between 0 and $5 \mathrm{~km}$, while the extent of depth averaging of the middle and lower crust is determined by evenly splitting the remaining thickness between $5 \mathrm{~km}$ and the Moho at each inversion point. (b-d) Same as panel (a) but for the middle and lower crust and upper mantle, respectively. All results shown in this figure are from Inversion Case 4 and correspond to inversions assuming the regional crust thickness model of Schmandt et al. (2015).

(e.g., Crampin, 1994; Shirzad \& Shomali, 2014; Xie et al., 2013; Xie et al., 2017). The middle crust shows only positive radial anisotropy, and its significance is characteristically greater than one standard deviation of the posterior. In contrast, the lower crust shows areas of negative anisotropy, but the significance of these measurements is typically smaller than one standard deviation of the posterior (Figure 7). 

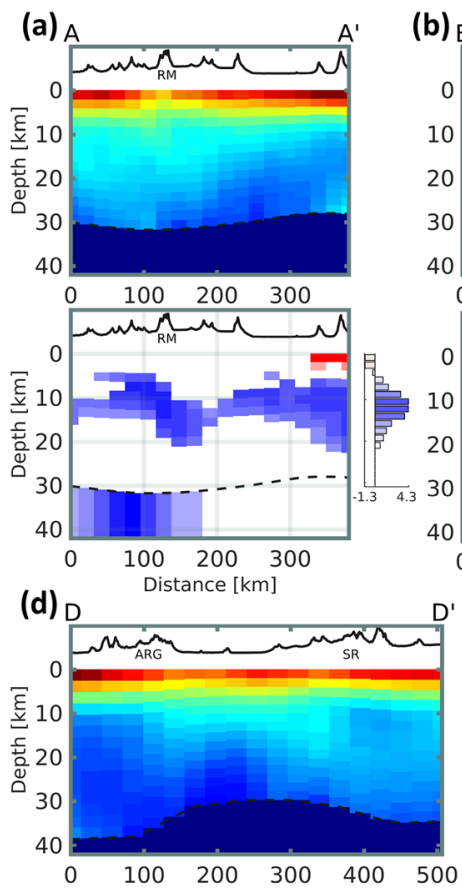

(b) ${ }_{B}$
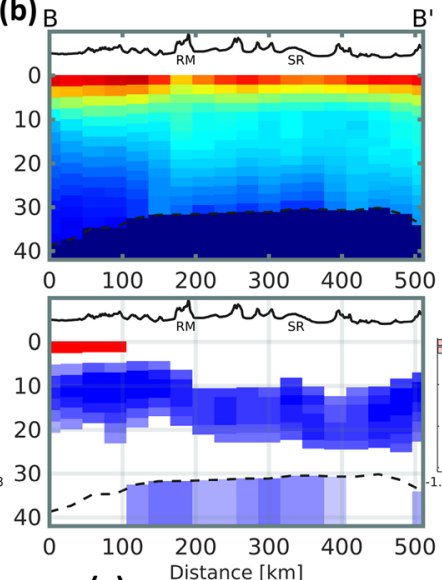

(e) $\mathrm{E}$

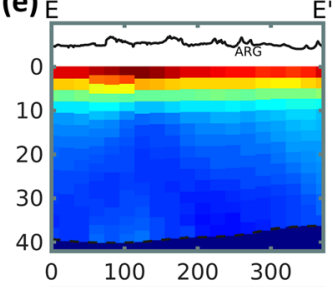

$E^{\prime} \quad(f)$
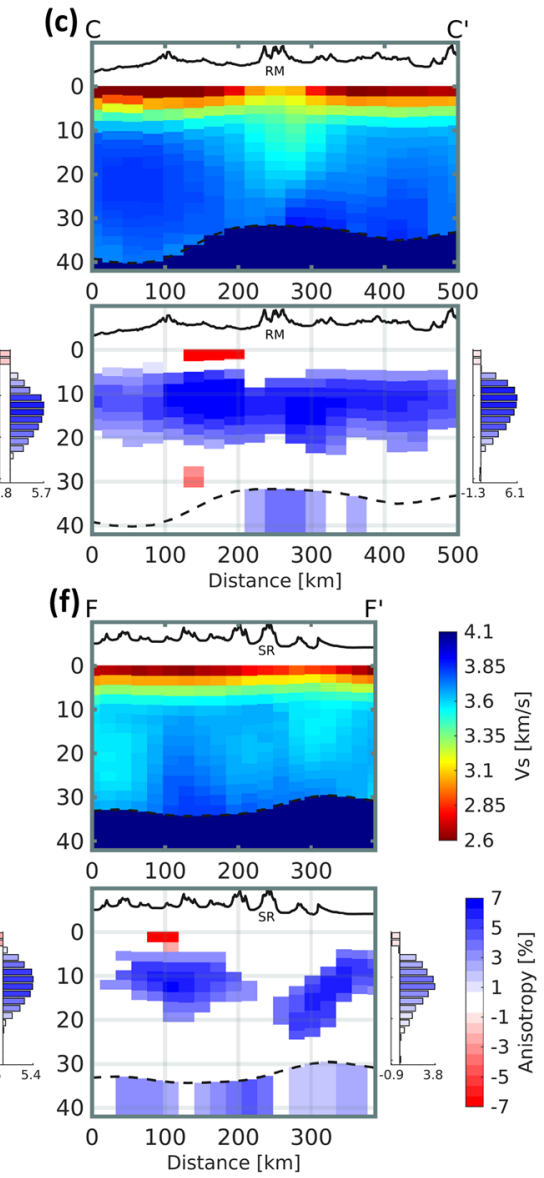

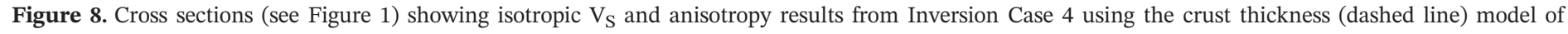

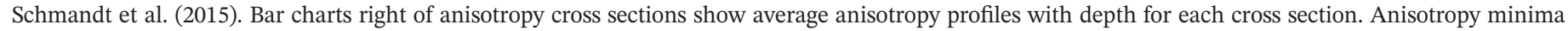

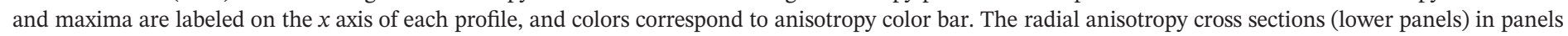

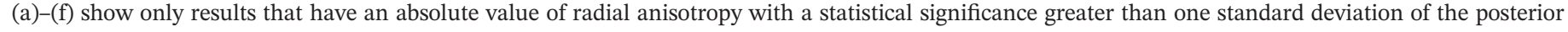
distribution. Topography is exaggerated three times in the profiles at the top of each panel.

Distinctive $V_{S}$ structure beneath the three MCCs is identified for isotropic $V_{S}$ in the upper crust, but the MCCs do not appear distinctive in radial anisotropy or middle to lower crustal isotropic $\mathrm{V}_{\mathrm{S}}$ (Figures 7 and 8). At upper crustal depths, the three MCCs exhibit isotropic $\mathrm{V}_{\mathrm{S}}$ that is $\sim 5-7 \%$ higher than the regional mean (Figure 7). In the middle crust, the most prominent isotropic $\mathrm{V}_{\mathrm{S}}$ features are relatively high $\mathrm{V}_{\mathrm{S}}(+3-5 \%)$ beneath the Snake River Plain and relatively low $\mathrm{V}_{\mathrm{S}}(-2 \%$ to $-4 \%)$ in an $\sim$ west-east trending corridor that crosses the Ruby Mountains MCC but extends across the study area (Figure 7). In a North-South cross section, $\mathrm{C}^{-\mathrm{C}^{\prime}}$, the low $\mathrm{V}_{\mathrm{S}}$ in the middle crust is colocated with the Ruby Mountains MCC (Figure 8c), but the map views show this is a larger feature almost orthogonal to the strike of the Ruby Mountains (Figure 7). In the lower crust, the Snake River Plain is underlain by relatively high $\mathrm{V}_{\mathrm{S}}(+4-6 \%)$ that extends southward across the physiographic boundary with the Basin and Range (Figure 7). At upper mantle depths, the highest $\mathrm{V}_{\mathrm{S}}$ is found in the southwest portion of the study area toward the center of the Basin and Range, and the lowest $V_{S}$ is found near the northwestern edge of the Colorado Plateau (Figure 7). The patterns of isotropic $V_{S}$ variations in the crust are consistent with prior tomography studies using TA data (e.g., Moschetti et al., 2010a, 2010b; Schmandt et al., 2015; Shen \& Ritzwoller, 2016). Radial anisotropy cross sections highlight the widespread positive radial anisotropy (+3-5\%) that forms a channel at middle crustal depths (Figure 8). In general, the magnitude and depth of radial anisotropy do not abruptly change near the MCCs. However, there is one notable local disruption of the middle crustal positive radial anisotropy channel near the Snake Range MCC (Figures 8d and 8f). 
(a)
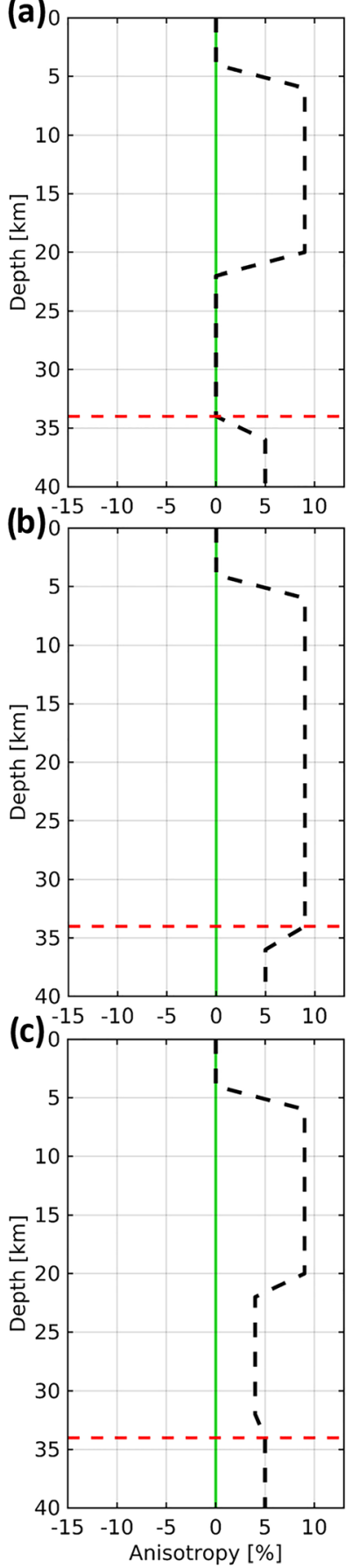

$\begin{array}{ll}- \text { - } & \text { Input } \\ \text { - Observation } & \text { Synthetic } \\ \text {-- } & \text { Synthe }\end{array}$
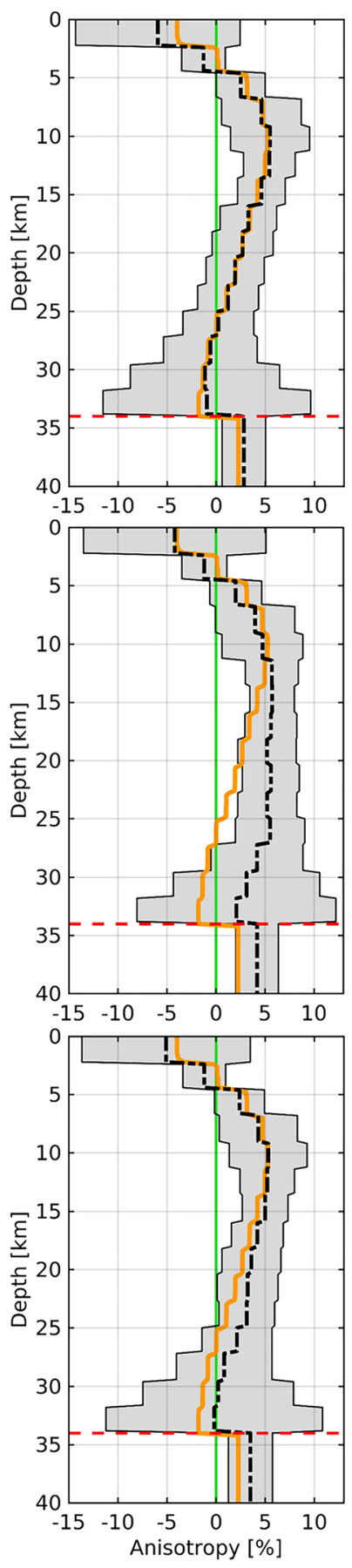

$$
\text { Anisotropy [\%] }
$$

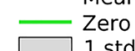

$\square$
$\square$
1 std

Figure 9. Synthetic resolution tests. (a) Left panel shows resolution test input (dashed line) of 9\% radial anisotropy from 6-22 km and 5\% in the upper mantle. Right panel shows resulting mean radial anisotropy model (dash-dotted line) from the forward calculation and one sigma corridor (shaded gray region) of the modeled posterior distribution. Orange line shows observed mean model from Inversion Case 4. (b) Same as panel (a) but with $9 \%$ radial anisotropy throughout the crust as input. (c) Same as panel (b) but with $4 \%$ radial anisotropy in the lower crust, 22 to $34 \mathrm{~km}$.
Perhaps the most important new result from this study is the evidence suggesting depth-dependent radial anisotropy in the form of a regional middle-crustal channel of positive radial anisotropy ( 3-5\%). From a reductionist perspective, it is informative that the parameterization tests show the Rayleigh-Love discrepancy can be adequately resolved by only introducing positive radial anisotropy in the middle crust (b-splines 2 and/or 3). Additionally, a peak magnitude of radial anisotropy of $\sim 4 \%$ is sufficient if radial anisotropy is restricted to b-spline 2 or depths of $\sim 5-15 \mathrm{~km}$, whereas greater magnitudes of up to $10-15 \%$ are needed to explain the Rayleigh-Love discrepancy if radial anisotropy is only allowed deeper or shallower (Figure 6).

\subsection{Synthetic Resolution Tests}

Resolution tests using synthetic dispersion curves generated from known $\mathrm{V}_{\mathrm{S}}$ models confirm that a middle crustal channel of radial anisotropy is resolvable and provide insight into the optimal depth range and magnitude of anisotropy for matching the observational results. The synthetic $\mathrm{V}_{\mathrm{S}}$ model posterior that best matches the regional mean structures includes 9\% radial anisotropy from 6-22 $\mathrm{km}$ depth and 5\% radial anisotropy in the upper mantle (Figure 9a). A test with $9 \%$ radial anisotropy extending from $6 \mathrm{~km}$ to the Moho does not match the diminishing radial anisotropy with depth found in the inversion results based on observational data (Figure 9b). A test with weaker lower crustal radial anisotropy of $4 \%$ is also consistent with the regional mean from the observational results (Figure 9c). Therefore, although the magnitude of anisotropy in the lower crust is not as strong as it is in the middle crust, the dispersion data cannot discriminate whether lower crustal radial anisotropy is somewhat weaker than that of the middle crust or absent entirely.

\subsection{Uncertainties Due to Modeling Assumptions}

Perhaps the most important source of uncertainty in the results lies in the validity of the radial anisotropy assumption. In this study, transverse isotropy (referred to as hexagonal symmetry in crystallography) with a vertical symmetry axis is assumed. This assumption is approximately valid for many deformed crustal rock samples (Brownlee et al., 2017; Erdman et al., 2013) and is common in studies seeking to explore seismic anisotropy via the Rayleigh-Love discrepancy. In some studies, this is also referred to as "apparent radial anisotropy" (e.g., Feng \& Ritzwoller, 2019; Xie et al., 2015; Xie et al., 2017). However, different forms of anisotropy and spatial variations in the tilt of the symmetry axis are likely to be present based on common crustal lithologies (Almqvist \& Mainprice, 2017; Brownlee et al., 2017; Erdman et al., 2013; Tatham et al., 2008; Ward et al., 2012). Allowing for more complex forms of anisotropy, such as an oriented hexagonal or orthorhombic tensor, would come with the tradeoff of estimating a greater number of model parameters, and prior results find that our study area is relatively well suited to the simpler assumption of transverse isotropy. Xie et al. (2015) inverted surface wave dispersion and ellipticity measurements allowing for hexagonal anisotropy with a spatially variable tilt axis and found that dip angles of the symmetry axis are relatively small, $\sim 15-25^{\circ}$, in the northeastern Basin and Range compared to the western U.S. average, $\sim 25-30^{\circ}$. This would cause our estimates of radial anisotropy to be slightly underestimated compared to the oriented elastic tensor approach of Xie et al. (2015). The simpler approach 
adopted here allows for efficient testing of several parameterizations that provide new insights into the depth dependence of radial anisotropy.

Another source of modeling uncertainty is the assumption of an empirical $\mathrm{V}_{\mathrm{P}} / \mathrm{V}_{\mathrm{S}}$ scaling (Brocher, 2005), which could bias the radial anisotropy results especially in cases of strongly anomalous $\mathrm{V}_{\mathrm{P}} / \mathrm{V}_{\mathrm{S}}$ that might be associated with deep sedimentary basins or the alpha-beta quartz transition in thick continental crust (Gao \& Lekić, 2018). However, estimates of depth-averaged crustal $\mathrm{V}_{\mathrm{P}} / \mathrm{V}_{\mathrm{S}}$ for the study region range from 1.7-1.82 based on a filtered H-k stacking approach (Lowry \& Perez-Gussinye, 2011). This range is approximately consistent with the database used for the empirical scaling from Brocher (2005). Therefore, in the absence of strong constraints on 3-D $V_{P}$ across the study area, we consider the empirical $V_{P} / V_{S}$ scaling relationship a reasonable assumption. Future studies incorporating additional measurements such as Rayleigh wave ellipticity (e.g., Gao \& Lekić, 2018; Lin et al., 2014) and $P$ wave reflectivity from ambient noise or coda autocorrelation (e.g., Delph et al., 2019; Gorbatov et al., 2012; Tibuleac \& von Seggern, 2012) offer opportunities to better mitigate tradeoffs between $\mathrm{V}_{\mathrm{P}} / \mathrm{V}_{\mathrm{S}}$ and crustal radial anisotropy.

\section{Discussion}

\subsection{Upper Mantle}

The surface wave period range used here (5-30 s) is most sensitive to crustal structure, but due to tradeoffs between lower crust and upper mantle structure, it is worth noting that the isotropic and anisotropic upper mantle results from this study are consistent with previous studies incorporating longer period measurements. High isotropic $\mathrm{V}_{\mathrm{S}}, \sim 4.3-4.4 \mathrm{~km} / \mathrm{s}$, in the uppermost mantle of the southwest portion of the study region agrees with prior $\mathrm{V}_{\mathrm{S}}$ tomography incorporating longer period surface waves and receiver functions (Shen \& Ritzwoller, 2016) and appears to be correlated with positive radial anisotropy in the same region (Figure 7). The results presented here also confirm that positive radial anisotropy of $\sim 2-5 \%$ is widespread in the uppermost mantle beneath the Basin and Range as found by recent long period waveform tomography (Clouzet et al., 2018; Yuan et al., 2014; Zhu et al., 2017).

\subsection{Links Between MCCs and $\mathrm{V}_{\mathrm{S}}$ Structure}

The anomalous degree of exhumation and extension evident at the surface in MCCs motivates inquiry into how MCC formation is manifested in subsurface $\mathrm{V}_{\mathrm{S}}$ structure. The three MCCs in the study area are closely correlated with high $\mathrm{V}_{\mathrm{S}},+4-7 \%$, in the upper crust (Figure 7). Continental crustal $\mathrm{V}_{\mathrm{S}}$ generally increases with depth (Christensen \& Mooney, 1995; Laske et al., 2013; Shen \& Ritzwoller, 2016; Tesauro et al., 2014), and in these locations, crustal rocks have been exhumed from the middle to lower crust to the surface. We therefore interpret these high $\mathrm{V}_{\mathrm{S}}$ regions to be a simple consequence of the locally anomalous exhumation (Figure 7a). Comparison of the average $\mathrm{V}_{\mathrm{S}}$ structure beneath the three MCCs with the average across the study area further shows the distinctly higher $\mathrm{V}_{\mathrm{S}}$ in the upper crust (Figure 10). In contrast, middle to lower crustal $\mathrm{V}_{\mathrm{S}}$ and radial anisotropy depth profiles averaged beneath the three MCCs are strikingly similar to those averaged across the study area (Figure 10). This similarity suggests that either MCC formation had little effect on deep crustal structure $\left(\mathrm{V}_{\mathrm{S}}\right.$ and anisotropy) or that the effect of MCC formation on deep crustal structure has been overprinted.

Models of MCC formation, particularly for rapidly exhumed MCCs, predict locally subvertical flow lines associated with anomalous levels of exhumation and partial melting of the middle crust (Rey et al., 2009a, 2009b). In the majority of the region surrounding MCCs, subhorizontal strain in the ductile crust is expected to dominate and supply the crustal mass necessary to balance rapid exhumation (Tirel et al., 2008; Wu et al., 2015; Wu \& Lavier, 2016). Subvertical strain organization in a transverse isotropy (or hexagonal symmetry) paradigm would likely produce a negative radial anisotropy signal locally beneath the MCCs or at least diminish the regionally prevalent positive radial anisotropy due to spatial averaging of complex structural transitions (e.g., Okaya et al., 2018). However, we generally do not find distinctly weaker or negative radial anisotropy beneath the three MCCs. Instead, they generally exhibit positive radial anisotropy in the middle crust and weaker radial anisotropy in the lower crust, similar to the surrounding region. The 70-km spacing of the TA may limit detection of local $\mathrm{V}_{\mathrm{S}}$ variations in the middle to lower crust beneath the Snake Range and ARG, but the dense $\sim 5-10 \mathrm{~km}$ spacing of the RMSE array is capable of resolving distinctive local $V_{S}$ structure if it exists beneath the Ruby Mountains. Additionally, we note that the available 

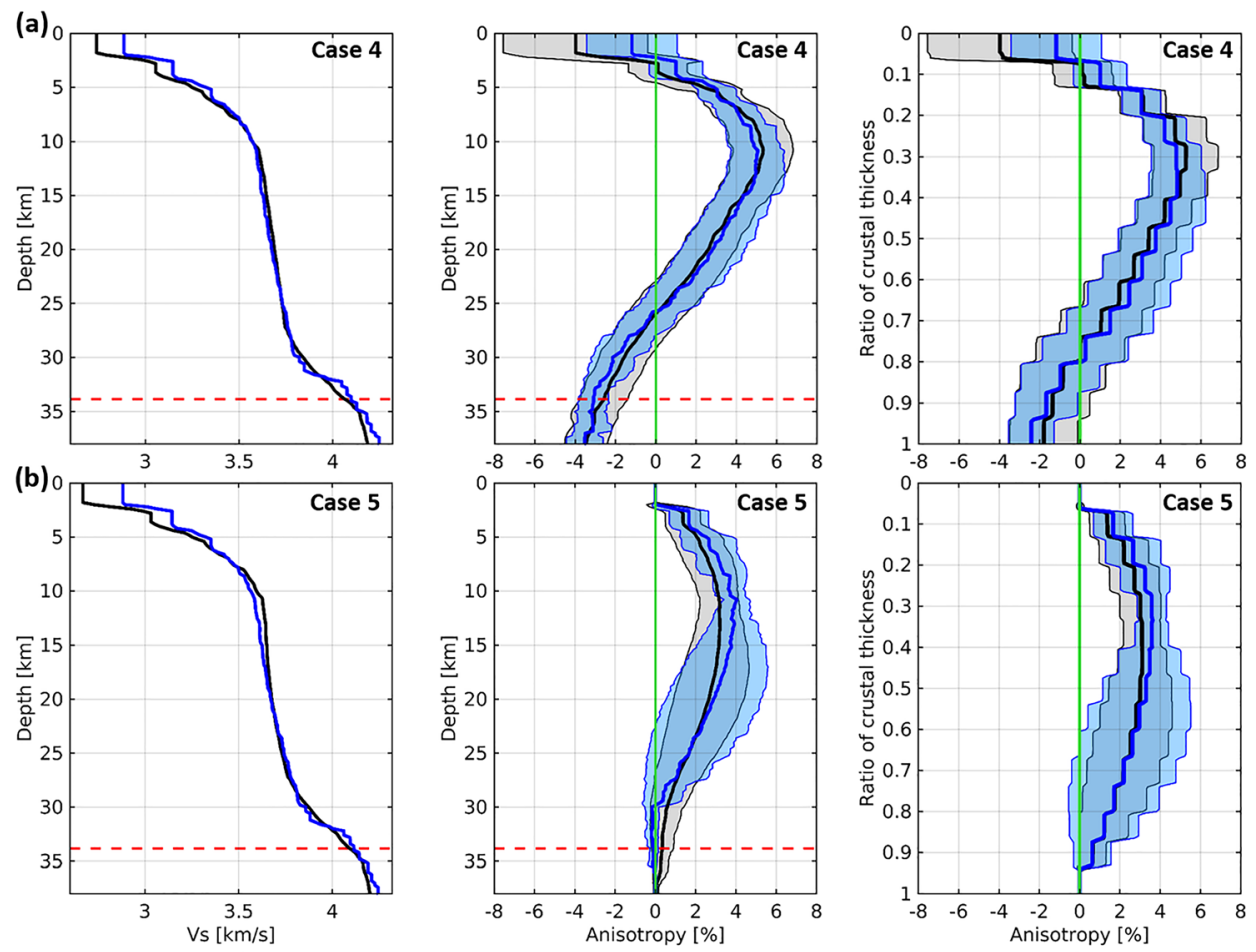

一NBR -

Figure 10. Comparison of $\mathrm{V}_{\mathrm{S}}$ structure beneath MCCs and the surrounding region. (a) Left panel shows mean isotropic $\mathrm{V}_{\mathrm{S}}$ profiles of the regional northern Basin and Range (black lines) and subset MCCs (blue lines). Notice high $\mathrm{V}_{\mathrm{S}}$ in the upper crust of the MCC profile relative to the northern Basin and Range. Center panel shows mean crustal radial anisotropy depth profiles of the regional northern Basin and Range (black lines) and subset MCCs (blue lines) from Inversion

Case 4. Shaded gray and blue regions are one sigma corridors of the northern Basin and Range and subset MCCs, respectively. Notice similarity in magnitude and distribution between the northern Basin and Range and MCC profiles. There are relatively few profiles that extend to depths greater than $35 \mathrm{~km}$, and therefore, the number of measurements included in the mean profile decreases with increasing depth. In the absence of depth averaging, the $~ 5 \%$ peak magnitude of anisotropy observed here surpasses the depth-averaged middle crust mean radial anisotropy of the map area, $\overline{\boldsymbol{x}}=4.16 \%$, as reported in Figure $7 \mathrm{~b}$. Right panel is same as center panel but normalized to crustal thickness. Notice largely isotropic behavior of lower crust relative to the middle crust. (b) Same as panel (a) but for Inversion Case 5. Anisotropy peaks in the middle crust in Inversion Cases 4 and 5 demonstrating similarity in the depth distribution of anisotropy.

seismic sampling is sufficient to detect locally higher upper crustal isotropic $\mathrm{V}_{\mathrm{S}}$ associated with all three MCCs. To explain the absence of distinctive structure ( $\mathrm{V}_{\mathrm{S}}$ and anisotropy) in the middle to lower crust, we suggest that ductile deformation promoted by a hot geotherm during and after middle Miocene regional-scale extension of the Basin and Range effectively homogenized deep crustal $\mathrm{V}_{\mathrm{S}}$ structure near the MCCs.

\subsection{Concentration of Anisotropy in a Middle Crustal Channel}

Prior studies established the presence of positive radial anisotropy in the Basin and Range crust (Moschetti et al., 2010a; Xie et al., 2015). One of the main goals of this study is to evaluate potential depth dependence of radial anisotropy to provide insight regarding the deformation regimes and compositions that are most likely to contribute to the development of large-scale crustal radial anisotropy. The results from several different inversion parameterization tests provide evidence that the Rayleigh-Love discrepancy in the northeastern Basin and Range is most simply addressed by a channel of positive radial anisotropy in the middle crust from $\sim 6-22 \mathrm{~km}$ depth (Figures 9 and 10). By simplicity we mean that radial anisotropy is only required in a subset of the crust and that a relatively small magnitude of anisotropy is sufficient to simultaneously fit the Rayleigh and Love wave dispersion data (Figures 4 and 5).

Below we consider potential reasons why radial anisotropy may be focused at middle crustal depths by discussing the potential roles of depth-dependent crustal composition and rheology. Mineralogical composition is a key consideration because it controls the potential magnitude of CPO development and predicts how a particular strain orientation would manifest itself in measurements of seismic radial anisotropy (e.g., 
Erdman et al., 2013; Ward et al., 2012). A conventional perspective is that the middle crust has a felsic to intermediate bulk composition largely containing amphibolite facies rocks and the lower crust has a mafic to intermediate bulk composition largely containing granulite facies rocks (Rudnick \& Fountain, 1995). However, the prevalence of relatively mafic lower continental crust remains a subject of debate (Hacker et al., 2015). Rheology is expected to vary with depth from an elastic upper crust that hosts frictional fault-controlled deformation to a time-dependent ductile middle to lower crust that hosts flow within shear zones or distributed throughout larger volumes (e.g., Bürgmann \& Dresen, 2008; Kohlstedt et al., 1995; Thatcher \& Pollitz, 2008). Composition and rheology are used here as a framework for discussion, but they are not independent. They are strongly linked by depth-dependent temperature and pressure conditions that change the relevant constitutive relationships and determine the stability of specific minerals.

From a compositional perspective, studies of seismic anisotropy in the continental crust often highlight the potential importance of CPO in mica-rich foliated metamorphic rocks because they are abundant, and single crystal mica is one of the most anisotropic crustal minerals (Lloyd et al., 2009; Rey et al., 1994; Weiss et al., 1999). Hexagonal symmetry (or transverse isotropy) is a valid assumption for single crystal mica, and it remains an effective approximation for many bulk rock samples with abundant mica (Bostock \& Christensen, 2012; Brownlee et al., 2017; Erdman et al., 2013; Lloyd et al., 2009; Nishizawa \& Yoshino, 2001). Amphibole is another common crustal mineral with potential to contribute to spatially averaged crustal seismic anisotropy (Brownlee et al., 2017; Tatham et al., 2008). However, single crystal amphiboles are much less anisotropic than micas, and amphibole-rich rocks commonly exhibit a component of orthorhombic symmetry (Brownlee et al., 2017) which would not be accurately represented with radial anisotropy. Quartz, in aggregate, is not likely to develop strong CPO in high-strain environments (Rahl \& Skemer, 2016), but it can destructively interfere with bulk anisotropy in lithologies with mica or amphibole (Ward et al., 2012). Mica-bearing metamorphic rocks are generally abundant in the middle crust, and rock samples exhumed from the Ruby Mountains MCC exhibit $4-19 \% \mathrm{~V}_{\mathrm{S}}$ anisotropy that is positively correlated with mica content (Erdman et al., 2013).

We suggest that mica-bearing metamorphic rocks with a subhorizontal foliation (subvertical slow-axis symmetry) are a viable explanation for the observed middle crustal positive radial anisotropy signal. Geodynamic models of regional-scale extension including core complex development (Tirel et al., 2008; Wu et al., 2015; Wu \& Lavier, 2016) and seismic reflection imaging support the prevalence of subhorizontal fabrics in the middle crust due to low-angle detachment faults and shear zones (Hauser et al., 1987; Holbrook et al., 1991; Klemperer et al., 1986; McCarthy, 1986; Rey, 1993; Stoerzel \& Smithson, 1998; Valasek et al., 1989). Weaker radial anisotropy in the lower crust is consistent with the interpretation that mica-bearing metamorphic rocks are a major contributor to the middle crustal channel of positive radial anisotropy. This is because higher temperatures $\left(>600-700^{\circ} \mathrm{C}\right)$ approaching the Moho would lead to diminished abundance of hydrous phases like micas in granulite facies lower crust (e.g., Mahan, 2006).

Rheological variations with depth may also contribute to the depth-dependent radial anisotropy in the study area. At geological timescales, ductile flow is expected in the middle and lower crust of the Miocene-topresent Basin and Range (e.g., Thatcher \& Pollitz, 2008; Tirel et al., 2008). However, decreasing shear stress and effective viscosity with depth, and increasing temperature with depth, could alter the potential for generation of large-scale seismic anisotropy. Onset of dislocation creep at lower stress conditions in the hotter lower crust favors larger dynamically recrystallized grain sizes and more distributed deformation, whereas onset of creep at higher stress conditions in the middle crust favors grain size reduction that leads to weakening and strain localization (Behr \& Platt, 2011; Cooper et al., 2017; Stipp \& Tullis, 2003). To first order, textures, fabrics, and compositions of middle and lower crustal rocks obtained from Basin and Range MCCs reflect this transition (Figure 11; Cooper et al., 2017). Cooper et al. (2017) identified two major rheological boundaries in Basin and Range MCCs, the BDT and a deeper temperature-dependent boundary referred to as the localized-distributed transition (LDT).

In this context, we suggest that positive radial anisotropy may be more effectively generated in localized shear zones closer to the top of the ductile deformation region in the middle crust. A regional median heat flux of $79 \mathrm{~mW} / \mathrm{m}^{2}$ (Hasterok \& Chapman, 2007) and thermal conductivity between 2.2 and $3.3 \mathrm{~W} / \mathrm{mK}$ (Whittington et al., 2009) corresponds to a geothermal gradient range of $\sim 25-35^{\circ} \mathrm{C} / \mathrm{km}$. Taking the $\sim 300^{\circ} \mathrm{C}$ isotherm as a proxy (e.g., Cooper et al., 2017), we estimate a modern BDT depth range of 

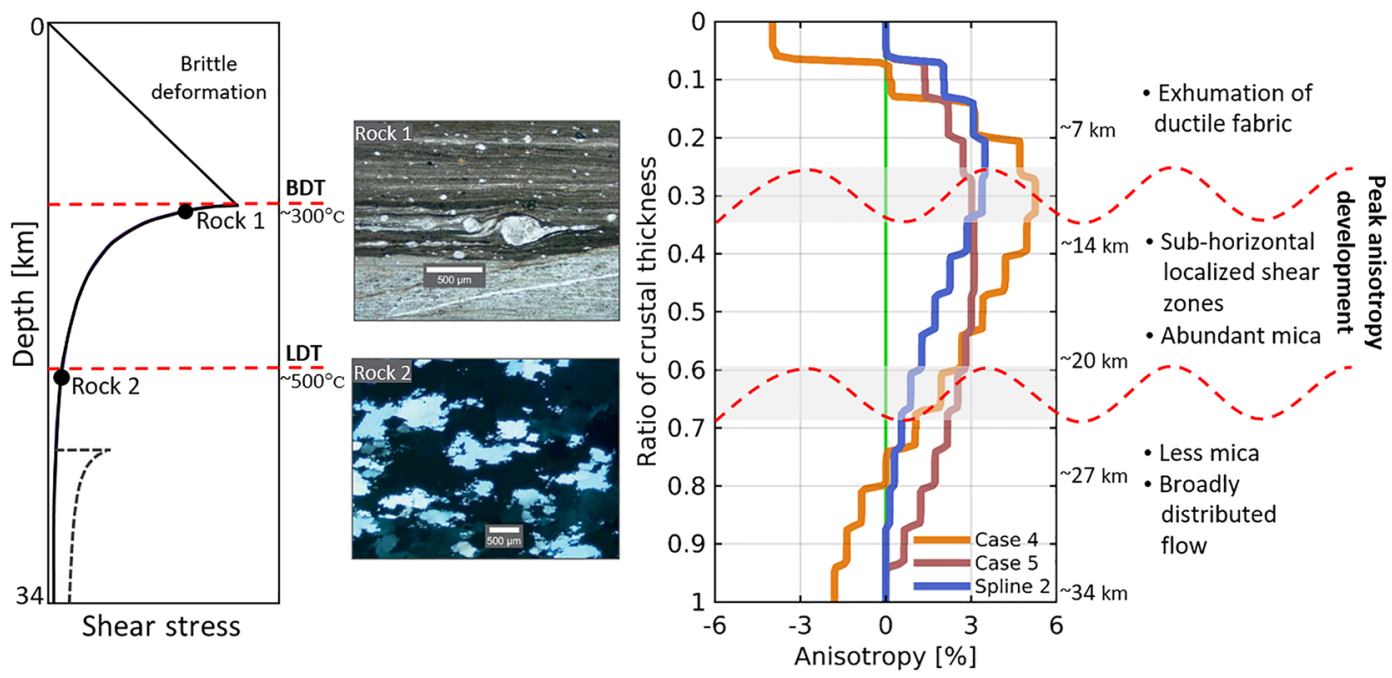

Figure 11. Synthesis of results. Left panel shows typical crustal strength profile and approximate depth ranges at which the brittle to ductile transition (BDT) and localized distributed transition (LDT) occur (dashed red lines) in the Basin and Range. Possible mafic addition to the lower crust is represented with a step in the lower crust (black dashed line). Approximate temperatures of the BDT and LDT are labeled and are adopted from Cooper et al. (2017). Center shows microphotographs (originally from Platt et al. (2015) but also used in Cooper et al. (2017)) of endmember middle (Rock 1) and lower (Rock 2) crustal rock samples exhumed from the Ruby Mountains MCC. These examples illustrate that middle crust commonly exhibits stronger fabric development compared to the lower crust. Depth and stress environments from which the rocks were exhumed are labeled on crustal strength profile. As temperature increases and viscosity decreases with depth, mica is lost, grains grow larger, and distributed deformation diminishes anisotropy, producing layering fabrics. Right panel shows study area mean anisotropy distribution with depth normalized to crustal thickness for Inversion Cases 4 and 5, and the inversion that allows only b-spline 2 to be anisotropic. Approximate depth ranges are labeled every 0.2 ratio of crustal thickness. Approximate depth ranges of peak anisotropy development, preservation after exhumation, and loss with increasing depth as discussed in the text are indicated on the right side of the panel.

2-12 km (Figure 11). Results indicating that the midcrustal channel of anisotropy extends above the estimated BDT, $\sim 6 \mathrm{~km}$ depth, suggests preservation of anisotropy in rocks that were deformed below the BDT and have subsequently been exhumed. Decaying strength of anisotropy in the lower crust may reflect the gradual LDT below which deformation is distributed across larger volumes and recrystallization is more rapid. The $\sim 500^{\circ} \mathrm{C}$ temperature of the inferred LDT in the Basin and Range is somewhat cooler than the petrologic transition to relatively mica-poor granulite facies, $\sim 600-700^{\circ} \mathrm{C}$. The similar depths of such boundaries would not likely be resolvable with dispersion data alone. Therefore, it is not feasible, based on depth alone, to determine if the rheological or compositional transition has a more important influence on radial anisotropy.

The history of magmatism in the Basin and Range is another important factor in evaluating the potential compositional and rheological origins of depth-dependent radial anisotropy. Substantial influx of mafic melt into the lower crust is expected during the voluminous Eocene-Miocene ignimbrite flare-up (e.g., Best \& Christiansen, 1991; Gans, 1987). This event likely had long-lasting consequences on crustal composition and rheology. Following flat-slab subduction during the Laramide orogeny, the regional lithosphere was likely cooler and contained more abundant hydrous minerals (Humphreys et al., 2003), but subsequent heating and flux of melt through the lithosphere would have dehydrated the lower crust and promoted a more mafic bulk composition (Gans, 1987). A dry lower crust in the contemporary Basin and Range is consistent with a scenario in which decreasing mica content in the lower crust leads to decreasing radial anisotropy.

Mafic intrusions would have competing effects on lower crustal rheology through thermal weakening that decays with time superimposed on long-term addition of primitive basalt or cumulate compositions that are more viscous than typical intermediate composition crust (e.g., Schutt et al., 2018). Seismic reflectivity of the Basin and Range crust peaks in the middle crust, but weaker subhorizontal reflectors are still common in the lower crust and are frequently attributed to mafic intrusions (Holbrook et al., 1991; Klemperer et al., 1986; McCarthy, 1986). A more mafic lower crust following Miocene opening of the Basin and Range would complicate the possibility of a regionally extensive LDT. Expanding on this idea, the deeply exhumed rocks that Cooper et al. (2017) used to define the LDT may preferentially represent zones of 
weakness during MCC formation rather than modern regionally averaged rheology. Sill-like intrusions are interpreted to contribute to strong positive radial anisotropy in active magmatic systems as a result of shape-preferred orientation (SPO) due to large $\mathrm{V}_{\mathrm{S}}$ contrasts between partially molten and subsolidus crustal rocks (Harmon \& Rychert, 2015; Jaxybulatov et al., 2014; Jiang et al., 2018; Lynner et al., 2018). However, crystallized basaltic sills embedded in an intermediate to mafic lower crust may not have large enough velocity contrasts for SPO to cause detectable radial anisotropy (Schmandt et al., 2019). For example, strong positive radial anisotropy, $\sim 12 \%$, is found beneath Yellowstone caldera, but older calderas beneath the Snake River Plain are underlain by relatively isotropic crust (Jiang et al., 2018).

\section{Conclusion}

Rayleigh and Love wave dispersion measurements were inverted for radially anisotropic $\mathrm{V}_{\mathrm{S}}$ structure of the crust and uppermost mantle beneath an area of the northeastern Basin and Range including three MCCs. Tests of several parameterizations provided new evidence that positive radial anisotropy is strongest at depths of $\sim 8-20 \mathrm{~km}$ across the region. The three MCCs have distinctive high isotropic $\mathrm{V}_{\mathrm{S}}$ in the upper crust, but they do not interrupt the regional channel of radial anisotropy focused in the middle crust. Subhorizontal foliation (subvertical slow axis symmetry) of mica-bearing lithologies in ductile shear zones and detachments is a viable origin for the positive radial anisotropy focused in the middle crust. The decay of radial anisotropy with depth in the lower crust could result from decreased mica abundance as high temperatures and influx of mantle melts since the Oligocene favor a dry and increasingly mafic mean composition. Rheological transition to more broadly distributed viscous deformation at lower crustal high temperatures may also contribute to diminishing anisotropy with depth. The absence of distinctive radial anisotropy beneath the three MCCs suggests that anisotropy generated during peak metamorphism, which generally occurred in the Oligocene, was subsequently overprinted by regionally pervasive extensional deformation of the ductile crust during and after the middle Miocene. The results motivate further investigation of the depth dependence of crustal anisotropy in other areas of continental deformation to gain a global perspective on the relative importance among potential compositional and rheological contributions to crustal anisotropy.

\section{References}

The facilities of the Incorporated Research Institutions for Seismology (IRIS) Data Services, and specifically the IRIS Data Management Center (https://ds.iris.edu/ds/nodes/dmc/), were used for access to waveforms, related metadata, and/or derived products from seismograph networks used in this study (https://doi.org/ 10.7914/SN/TA; https://doi.org/ 10.7914/SN/YX_2010; https://doi.org/ 10.7932/BDSN; https://doi.org/ 10.7914/SN/CI; https://doi.org/ 10.7914/SN/IW; http://www.fdsn.org/ networks/detail/LB/; https://doi.org/ 10.7914/SN/US; https://doi.org/ 10.7914/SN/UU). IRIS Data Services are funded through the Seismological Facilities for the Advancement of Geoscience and EarthScope Proposal of the National Science Foundation (NSF) under Cooperative Agreement EAR-

1261681. S. Klemperer led the collection of the RMSE data and engaged in helpful discussions. J. Selverstone and W. Behr provided valuable feedback during the project. Two anonymous reviewers provided insightful comments that improved the presentation of the manuscript. This research was supported by NSF EAR1554908.
Almqvist, B. S., \& Mainprice, D. (2017). Seismic properties and anisotropy of the continental crust: Predictions based on mineral texture and rock microstructure. Reviews of Geophysics, 55, 367-433. https://doi.org/10.1002/2016RG000552

Babuska, V., \& Cara, M. (1991). Seismic anisotropy in the Earth (Vol. 10). Dordrecht, Netherlands: Springer Science \& Business Media.

Backus, G. E. (1962). Long-wave elastic anisotropy produced by horizontal layering. Journal of Geophysical Research, 67(11), 4427-4440. https://doi.org/10.1029/JZ067i011p04427

Barnes, C. G., Burton, B. R., Burling, T. C., Wright, J. E., \& Karlsson, H. R. (2001). Petrology and geochemistry of the late Eocene Harrison pass pluton, Ruby Mountains core complex, northeastern Nevada. Journal of Petrology, 42(5), 901-929. https://doi.org/10.1093/petrology/42.5.901

Behr, W. M., \& Platt, J. P. (2011). A naturally constrained stress profile through the middle crust in an extensional terrane. Earth and Planetary Science Letters, 303(3-4), 181-192. https://doi.org/10.1016/j.epsl.2010.11.044

Bennett, R. A., Wernicke, B. P., Niemi, N. A., Friedrich, A. M., \& Davis, J. L. (2003). Contemporary strain rates in the northern Basin and Range province from GPS data. Tectonics, 22(2), 1008. https://doi.org/10.1029/2001tc001355

Bensen, G. D., Ritzwoller, M. H., Barmin, M. P., Levshin, A. L., Lin, F., Moschetti, M. P., et al. (2007). Processing seismic ambient noise data to obtain reliable broad-band surface wave dispersion measurements. Geophysical Journal International, 169(3), 1239-1260. https://doi. org/10.1111/j.1365-246X.2007.03374.X

Best, M. G., \& Christiansen, E. H. (1991). Limited extension during peak tertiary volcanism, Great Basin of Nevada and Utah. Journal of Geophysical Research, 96(B8), 13,509-13,528. https://doi.org/10.1029/91JB00244

Block, L., \& Royden, L. H. (1990). Core complex geometries and regional scale flow in the lower crust. Tectonics, 9(4), 557-567. https://doi. org/10.1029/TC009i004p00557

Bostock, M. G., \& Christensen, N. I. (2012). Split from slip and schist: Crustal anisotropy beneath northern Cascadia from non-volcanic tremor. Journal of Geophysical Research, 117, B08303. https://doi.org/10.1029/2011JB009095

Brocher, T. M. (2005). Empirical relations between elastic wavespeeds and density in the Earth's crust. Bulletin of the Seismological Society of America, 95(6), 2081-2092. https://doi.org/10.1785/0120050077

Brownlee, S. J., Schulte-Pelkum, V., Raju, A., Mahan, K., Condit, C., \& Orlandini, O. F. (2017). Characteristics of deep crustal seismic anisotropy from a compilation of rock elasticity tensors and their expression in receiver functions. Tectonics, 36, 1835-1857. https://doi. org/10.1002/2017TC004625

Buehler, J. S., \& Shearer, P. M. (2017). Uppermost mantle seismic velocity structure beneath USArray. Journal of Geophysical Research: Solid Earth, 122, 436-448. https://doi.org/10.1002/2016JB013265

Bürgmann, R., \& Dresen, G. (2008). Rheology of the lower crust and upper mantle: Evidence from rock mechanics, geodesy, and field observations. Annual Review of Earth and Planetary Sciences, 36(1), 531-567. https://doi.org/10.1146/annurev.earth.36.031207.124326

Camp, V. E., Pierce, K. L., \& Morgan, L. A. (2015). Yellowstone plume trigger for Basin and Range extension, and coeval emplacement of the Nevada-Columbia Basin magmatic belt. Geosphere, 11(2), 203-225. https://doi.org/10.1130/GES01051.1 
Cheng, C., Chen, L., Yao, H., Jiang, M., \& Wang, B. (2013). Distinct variations of crustal shear wave velocity structure and radial anisotropy beneath the North China Craton and tectonic implications. Gondwana Research, 23(1), 25-38. https://doi.org/10.1016/j.gr.2012.02.014

Christensen, N. I., \& Mooney, W. D. (1995). Seismic velocity structure and composition of the continental crust: A global view. Journal of Geophysical Research, 100(B6), 9761-9788. https://doi.org/10.1029/95JB00259

Clouzet, P., Masson, Y., \& Romanowicz, B. (2018). Box tomography: First application to the imaging of upper-mantle shear velocity and radial anisotropy structure beneath the North American continent. Geophysical Journal International, 213(3), 1849-1875. https://doi. org/10.1093/gji/ggy078

Colgan, J. P., \& Henry, C. D. (2009). Rapid middle Miocene collapse of the Mesozoic orogenic plateau in North-Central Nevada. International Geology Review, 51(9-11), 920-961. https://doi.org/10.1080/00206810903056731

Colgan, J. P., Howard, K. A., Fleck, R. J., \& Wooden, J. L. (2010). Rapid middle Miocene extension and unroofing of the southern Ruby Mountains, Nevada. Tectonics, 29, TC6022. https://doi.org/10.1029/2009TC002655

Compton, R. R., Todd, V. R., Zartman, R. E., \& Naeser, C. W. (1977). Oligocene and Miocene metamorphism, folding, and low-angle faulting in northwestern Utah. Geological Society of America Bulletin, 88(9), 1237-1250. https://doi.org/10.1130/0016-7606(1977)88\% 3C1237:OAMMFA\%3E2.0.CO;2

Coney, P. J., \& Harms, T. A. (1984). Cordilleran metamorphic core complexes: Cenozoic extensional relics of Mesozoic compression. Geology, 12(9), 550-554. https://doi.org/10.1130/0091-7613(1984)12\%3C550:CMCCCE\%3E2.0.CO;2

Cooper, F. J., Platt, J. P., \& Behr, W. M. (2017). Rheological transitions in the middle crust: Insights from cordilleran metamorphic core complexes. Solid Earth, 8(1), 199-215. https://doi.org/10.5194/se-8-199-2017

Crampin, S. (1994). The fracture criticality of crustal rocks. Geophysical Journal International, 118(2), 428-438. https://doi.org/10.1111/ j.1365-246X.1994.tb03974.x

Crittenden, M. D., Coney, P. J., Davis, G. H., \& Davis, G. H. (1980). Cordilleran metamorphic core complexes (Vol. 153, pp. 153-490). Boulder, CO: Geological Society of America Memoir.

Dalton, C. A., \& Gaherty, J. B. (2013). Seismic anisotropy in the continental crust of northwestern Canada. Geophysical Journal International, 193(1), 338-348. https://doi.org/10.1093/gji/ggs108

Delph, J. R., Levander, A., \& Niu, F. (2019). Constraining crustal properties using receiver functions and the autocorrelation of earthquake-generated body waves. Journal of Geophysical Research: Solid Earth, 124, 8981-8997. https://doi.org/10.1029/ 2019JB017929

Dewey, J. F. (1988). Extensional collapse of orogens. Tectonics, 7(6), 1123-1139. https://doi.org/10.1029/TC007i006p01123

Dreiling, J., Tilmann, F., Yuan, X., Giese, J., Rindraharisaona, E. J., Rümpker, G., \& Wysession, M. E. (2018). Crustal radial anisotropy and linkage to geodynamic processes: A study based on seismic ambient noise in southern Madagascar. Journal of Geophysical Research: Solid Earth, 123, 5130-5146. https://doi.org/10.1029/2017JB015273

Duret, F., Shapiro, N. M., Cao, Z., Levin, V., Molnar, P., \& Roecker, S. (2010). Surface wave dispersion across Tibet: Direct evidence for radial anisotropy in the crust. Geophysical Research Letters, 37, L16306. https://doi.org/10.1029/2010GL043811

Dziewonski, A. M., \& Anderson, D. L. (1981). Preliminary reference Earth model. Physics of the Earth and Planetary Interiors, 25(4), 297-356. https://doi.org/10.1016/0031-9201(81)90046-7

Egger, A. E., Dumitru, T. A., Miller, E. L., Savage, C. F., \& Wooden, J. L. (2003). Timing and nature of tertiary plutonism and extension in the Grouse Creek mountains, Utah. International Geology Review, 45(6), 497-532. https://doi.org/10.2747/0020-6814.45.6.497

Ekström, G. (2017). Short-period surface-wave phase velocities across the conterminous United States. Physics of the Earth and Planetary Interiors, 270, 168-175. https://doi.org/10.1016/j.pepi.2017.07.010

Ekström, G., Abers, G. A., \& Webb, S. C. (2009). Determination of surface-wave phase velocities across USArray from noise and Aki's spectral formulation. Geophysical Research Letters, 36, L18301. https://doi.org/10.1029/2009GL039131

Erdman, M. E., Hacker, B. R., Zandt, G., \& Seward, G. (2013). Seismic anisotropy of the crust: Electron-backscatter diffraction measurements from the Basin and Range. Geophysical Journal International, 195(2), 1211-1229. https://doi.org/10.1093/gji/ggt287

Feng, L., \& Ritzwoller, M. H. (2019). A 3-D shear velocity model of the crust and uppermost mantle beneath Alaska including apparent radial anisotropy. Journal of Geophysical Research: Solid Earth, 124, 10,468-10,497. https://doi.org/10.1029/2019JB018122

Fenneman, N. M. (1917). Physiographic subdivision of the United States. Proceedings of the National Academy of Sciences of the United States of America, 3(1), 17-22. https://doi.org/10.1073/pnas.3.1.17

Fu, Y. V., \& Li, A. (2015). Crustal shear wave velocity and radial anisotropy beneath the Rio Grande rift from ambient noise tomography. Journal of Geophysical Research: Solid Earth, 120, 1005-1019. https://doi.org/10.1002/2014JB011602

Gans, P. B. (1987). An open-system, two-layer crustal stretching model for the eastern Great Basin. Tectonics, 6(1), 1-12. https://doi.org/ 10.1029/TC006i001p00001

Gao, C., \& Lekić, V. (2018). Consequences of parametrization choices in surface wave inversion: Insights from transdimensional Bayesian methods. Geophysical Journal International, 215(2), 1037-1063. https://doi.org/10.1093/gji/ggy310

Gébelin, A., Mulch, A., Teyssier, C., Heizler, M., Vennemann, T., \& Seaton, N. C. (2011). Oligo-Miocene extensional tectonics and fluid flow across the Northern Snake Range detachment system, Nevada. Tectonics, 30, TC5010. https://doi.org/10.1029/2010TC002797

Gilbert, H. (2012). Crustal structure and signatures of recent tectonism as influenced by ancient terranes in the western United States. Geosphere, 8(1), 141-157. https://doi.org/10.1130/GES00720.1

Gorbatov, A., Saygin, E., \& Kennett, B. L. N. (2012). Crustal properties from seismic station autocorrelograms. Geophysical Journal International, 192(2), 861-870. https://doi.org/10.1093/gji/ggs064

Hacker, B. R., Kelemen, P. B., \& Behn, M. D. (2015). Continental lower crust. Annual Review of Earth and Planetary Sciences, 43(1), 167-205. https://doi.org/10.1146/annurev-earth-050212-124117

Hacker, B. R., Ritzwoller, M. H., \& Xie, J. (2014). Partially melted, mica-bearing crust in Central Tibet. Tectonics, 33, 1408-1424. https://doi. org/10.1002/2014TC003545

Haines, S. H., \& van der Pluijm, B. A. (2010). Dating the detachment fault system of the Ruby Mountains, Nevada: Significance for the kinematics of low-angle normal faults. Tectonics, 29, TC4028. https://doi.org/10.1029/2009TC002552

Hamilton, W., \& Myers, W. B. (1966). Cenozoic tectonics of the western United States. Reviews of Geophysics, 4(4), 509-549. https://doi.org/ 10.1029/RG004i004p00509

Hammond, W. C., \& Thatcher, W. (2004). Contemporary tectonic deformation of the Basin and Range province, western United States: 10 years of observation with the global positioning system. Journal of Geophysical Research, 109, B08403. https://doi.org/10.1029/ 2003JB002746

Hansen, S. M., Dueker, K., \& Schmandt, B. (2015). Thermal classification of lithospheric discontinuities beneath USArray. Earth and Planetary Science Letters, 431, 36-47. https://doi.org/10.1016/j.epsl.2015.09.009 
Harmon, N., \& Rychert, C. A. (2015). Seismic imaging of deep crustal melt sills beneath Costa Rica suggests a method for the formation of the Archean continental crust. Earth and Planetary Science Letters, 430, 140-148. https://doi.org/10.1016/j.epsl.2015.07.062

Hasterok, D., \& Chapman, D. S. (2007). Continental thermal isostasy: 2. Application to North America. Journal of Geophysical Research, 112, B0P6415. https://doi.org/10.1029/2006JB004664

Hastings, W. K. (1970). Monte Carlo sampling methods using Markov chains and their applications. Biometrika, 57(1), 97-109. https://doi. org/10.1093/biomet/57.1.97

Hauser, E., Potter, C., Hauge, T., Burgess, S., Burtch, S., Mutschler, J., et al. (1987). Crustal structure of eastern Nevada from COCORP deep seismic reflection data. Geological Society of America Bulletin, 99(6), 833-844. https://doi.org/10.1130/0016-7606(1987)99\%3C833: CSOENF\%3E2.0.CO;2

Herrmann, R. B. (2013). Computer programs in seismology: An evolving tool for instruction and research. Seismological Research Letters, 84(6), 1081-1088. https://doi.org/10.1785/0220110096

Hodges, K. V., Snoke, A. W., \& Hurlow, H. A. (1992). Thermal evolution of a portion of the Sevier hinterland: The northern Ruby Mountains-East Humboldt range and Wood Hills, northeastern Nevada. Tectonics, 11(1), 154-164. https://doi.org/10.1029/ $91 \mathrm{TC} 01879$

Holbrook, W. S., Catchings, R. D., \& Jarchow, C. M. (1991). Origins of deep crustal reflections: Implications of coincident seismic refraction and reflection data in Nevada. Geology, 19(2), 175-179. https://doi.org/10.1130/0091-7613(1991)019\%3C0175:OODCRI\%3E2.3.CO;2

Huang, H., Yao, H., \& van der Hilst, R. D. (2010). Radial anisotropy in the crust of SE Tibet and SW China from ambient noise interferometry. Geophysical Research Letters, 37, L21310. https://doi.org/10.1029/2010GL044981

Humphreys, E., Hessler, E., Dueker, K., Farmer, G. L., Erslev, E., \& Atwater, T. (2003). How Laramide-age hydration of North American lithosphere by the Farallon slab controlled subsequent activity in the western United States. International Geology Review, 45(7), 575-595. https://doi.org/10.2747/0020-6814.45.7.575

Jaxybulatov, K., Shapiro, N. M., Koulakov, I., Mordret, A., Landès, M., \& Sens-Schoenfelder, C. (2014). A large magmatic sill complex beneath the Toba caldera. Science, 346(6209), 617-619. https://doi.org/10.1126/science.1258582

Jiang, C., Schmandt, B., Farrell, J., Lin, F. C., \& Ward, K. M. (2018). Seismically anisotropic magma reservoirs underlying silicic calderas. Geology, 46(8), 727-730. https://doi.org/10.1130/G45104.1

Klemperer, S. L., Hauge, T. A., Hauser, E. C., Oliver, J. E., \& Potter, C. J. (1986). The Moho in the northern Basin and Range province, Nevada, along the COCORP 40 N seismic-reflection transect. Geological Society of America Bulletin, 97(5), 603-618. https://doi.org/ 10.1130/0016-7606(1986)97\%3C603:TMITNB\%3E2.0.CO;2

Kohlstedt, D. L., Evans, B., \& Mackwell, S. J. (1995). Strength of the lithosphere: Constraints imposed by laboratory experiments. Journal of Geophysical Research, 100(B9), 17587-17602. https://doi.org/10.1029/95JB01460

Konstantinou, A., Strickland, A., Miller, E., Vervoort, J., Fisher, C. M., Wooden, J., \& Valley, J. (2013). Synextensional magmatism leading to crustal flow in the Albion-Raft River-Grouse Creek metamorphic core complex, northeastern Basin and Range. Tectonics, 32, 1384-1403. https://doi.org/10.1002/tect.20085

Kreemer, C., Blewitt, G., \& Klein, E. C. (2014). A geodetic plate motion and global strain rate model. Geochemistry, Geophysics, Geosystems, 15, 3849-3889. https://doi.org/10.1002/2014GC005407

Laske, G., Masters, G., Ma, Z., \& Pasyanos, M. (2013). Update on CRUST1.0-A 1-degree Global Model of Earth's Crust, Abstract EGU20132658.

Leary, P. C., Crampin, S., \& McEvilly, T. V. (1990). Seismic fracture anisotropy in the Earth's crust: An overview. Journal of Geophysical Research, 95(B7), 11,105-11,114. https://doi.org/10.1029/JB095iB07p11105

Lee, J., Miller, E. L., \& Sutter, J. F. (1987). Ductile strain and metamorphism in an extensional tectonic setting: A case study from the Northern Snake Range, Nevada, USA. Geological Society, London, Special Publications, 28(1), 267-298. https://doi.org/10.1144/GSL. SP.1987.028.01.18

Lekić, V., \& Fischer, K. M. (2014). Contrasting lithospheric signatures across the western United States revealed by Sp receiver functions. Earth and Planetary Science Letters, 402, 90-98. https://doi.org/10.1016/j.epsl.2013.11.026

Levander, A., \& Miller, M. S. (2012). Evolutionary aspects of lithosphere discontinuity structure in the western US. Geochemistry, Geophysics, Geosystems, 13, Q0AK07. https://doi.org/10.1029/2012GC004056

Lin, F. C., Moschetti, M. P., \& Ritzwoller, M. H. (2008). Surface wave tomography of the western United States from ambient seismic noise: Rayleigh and Love wave phase velocity maps. Geophysical Journal International, 173(1), 281-298. https://doi.org/10.1111/j.1365246X.2008.03720.X

Lin, F. C., Ritzwoller, M. H., Yang, Y., Moschetti, M. P., \& Fouch, M. J. (2011). Complex and variable crustal and uppermost mantle seismic anisotropy in the western United States. Nature Geoscience, 4(1), 55-61. https://doi.org/10.1038/ngeo1036

Lin, F. C., Tsai, V. C., \& Schmandt, B. (2014). 3-D crustal structure of the western United States: Application of Rayleigh-wave ellipticity extracted from noise cross-correlations. Geophysical Journal International, 198(2), 656-670. https://doi.org/10.1093/gii/ggu160

Litherland, M. M., \& Klemperer, S. L. (2017). Crustal structure of the Ruby Mountains metamorphic core complex, Nevada, from passive seismic imaging. Geosphere, 13(5), 1506-1523. https://doi.org/10.1130/GES01472.1

Lloyd, G. E., Butler, R. W., Casey, M., \& Mainprice, D. (2009). Mica, deformation fabrics and the seismic properties of the continental crust. Earth and Planetary Science Letters, 288(1-2), 320-328. https://doi.org/10.1016/j.epsl.2009.09.035

Long, S. P. (2018). Geometry and magnitude of extension in the Basin and Range Province (39 N), Utah, Nevada, and California, USA: Constraints from a province-scale cross section. Geological Society of America Bulletin, 131(1-2), 99-119.

Lowry, A. R., \& Pérez-Gussinyé, M. (2011). The role of crustal quartz in controlling Cordilleran deformation. Nature, 471(7338), $353-357$. https://doi.org/10.1038/nature09912

Luo, Y., Xu, Y., \& Yang, Y. (2013). Crustal radial anisotropy beneath the Dabie Orogenic Belt from ambient noise tomography. Geophysical Journal International, 195(2), 1149-1164. https://doi.org/10.1093/gji/ggt281

Lynner, C., Beck, S. L., Zandt, G., Porritt, R. W., Lin, F. C., \& Eilon, Z. C. (2018). Midcrustal deformation in the Central Andes constrained by radial anisotropy. Journal of Geophysical Research: Solid Earth, 123, 4798-4813. https://doi.org/10.1029/2017JB014936

MacCready, T., Snoke, A. W., Wright, J. E., \& Howard, K. A. (1997). Mid-crustal flow during Tertiary extension in the Ruby Mountains core complex, Nevada. Geological Society of America Bulletin, 109(12), 1576-1594. https://doi.org/10.1130/0016-7606(1997)109\%3C1576: MCFDTE\%3E2.3.CO;2

Mahan, K. (2006). Retrograde mica in deep crustal granulites: Implications for crustal seismic anisotropy. Geophysical Research Letters, 33, L24301. https://doi.org/10.1029/2006GL028130

Mainprice, D., \& Nicolas, A. (1989). Development of shape and lattice preferred orientations: Application to the seismic anisotropy of the lower crust. Journal of Structural Geology, 11(1-2), 175-189. https://doi.org/10.1016/0191-8141(89)90042-4 
Matharu, G., Bostock, M. G., Christensen, N. I., \& Tromp, J. (2014). Crustal anisotropy in a subduction zone forearc: Northern Cascadia. Journal of Geophysical Research: Solid Earth, 119, 7058-7078. https://doi.org/10.1002/2014JB011321

McCarthy, J. (1986). Reflection profiles from the Snake Range metamorphic core complex: A window into the mid-crust. Reflection seismology: The continental crust, 14, 281-292. https://doi.org/10.1029/GD014p0281

McCarthy, J., \& Thompson, G. A. (1988). Seismic imaging of extended crust with emphasis on the western United States. Geological Society of America Bulletin, 100(9), 1361-1374. https://doi.org/10.1130/0016-7606(1988)100\%3C1361:SIOECW\%3E2.3.CO;2

McQuarrie, N., \& Wernicke, B. P. (2005). An animated tectonic reconstruction of southwestern North America since 36 Ma. Geosphere, 1(3), 147-172. https://doi.org/10.1130/GES00016.1

Mikulich, M. J., \& Smith, R. B. (1974). Seismic reflection and aeromagnetic surveys of the Great Salt Lake, Utah. Geological Society of America Bulletin, 85(6), 991-1002. https://doi.org/10.1130/0016-7606(1974)85\%3C991:SRAASO\%3E2.0.CO;2

Miller, E. L., Dumitru, T. A., Brown, R. W., \& Gans, P. B. (1999). Rapid Miocene slip on the Snake Range-Deep Creek range fault system, east-central Nevada. Geological Society of America Bulletin, 111(6), 886-905. https://doi.org/10.1130/0016-7606(1999)111\%3C0886: RMSOTS\%3E2.3.CO;2

Moschetti, M. P., Ritzwoller, M. H., Lin, F., \& Yang, Y. (2010a). Seismic evidence for widespread western-US deep-crustal deformation caused by extension. Nature, 464(7290), 885-889. https://doi.org/10.1038/nature08951

Moschetti, M. P., Ritzwoller, M. H., Lin, F. C., \& Yang, Y. (2010b). Crustal shear wave velocity structure of the western United States inferred from ambient seismic noise and earthquake data. Journal of Geophysical Research, 115, B10306. https://doi.org/10.1029/2010JB007448

Mosegaard, K., \& Tarantola, A. (1995). Monte Carlo sampling of solutions to inverse problems. Journal of Geophysical Research, 100(B7), 12,431-12,447. https://doi.org/10.1029/94JB03097

Nishizawa, O., \& Yoshino, T. (2001). Seismic velocity anisotropy in mica-rich rocks: An inclusion model. Geophysical Journal International, 145(1), 19-32. https://doi.org/10.1111/j.1365-246X.2001.00331.X

Ojo, A. O., Ni, S., \& Li, Z. (2017). Crustal radial anisotropy beneath Cameroon from ambient noise tomography. Tectonophysics, 696, 37-51. https://doi.org/10.1016/j.tecto.2016.12.018

Okaya, D., Vel, S. S., Song, W. J., \& Johnson, S. E. (2018). Modification of crustal seismic anisotropy by geological structures (“structural geometric anisotropy”). Geosphere, 15(1), 146-170. https://doi.org/10.1130/ges01655.1

Panning, M., \& Romanowicz, B. (2006). A three-dimensional radially anisotropic model of shear velocity in the whole mantle. Geophysical Journal International, 167(1), 361-379. https://doi.org/10.1111/j.1365-246X.2006.03100.x

Pérouse, E., \& Wernicke, B. P. (2017). Spatiotemporal evolution of fault slip rates in deforming continents: The case of the Great Basin region, northern Basin and Range province. Geosphere, 13(1), 112-135. https://doi.org/10.1130/GES01295.1

Platt, J. P., Behr, W. M., \& Cooper, F. J. (2015). Metamorphic core complexes: Windows into the mechanics and rheology of the crust. Journal of the Geological Society, 172(1), 9-27. https://doi.org/10.1144/jgs2014-036

Rahl, J. M., \& Skemer, P. (2016). Microstructural evolution and rheology of quartz in a mid-crustal shear zone. Tectonophysics, 680, 129-139. https://doi.org/10.1016/j.tecto.2016.05.022

Rey, P. (1993). Seismic and tectono-metamorphic characters of the lower continental crust in Phanerozoic areas: A consequence of post-thickening extension. Tectonics, 12(2), 580-590. https://doi.org/10.1029/92TC01568

Rey, P., Vanderhaeghe, O., \& Teyssier, C. (2001). Gravitational collapse of the continental crust: Definition, regimes and modes. Tectonophysics, 342(3-4), 435-449. https://doi.org/10.1016/S0040-1951(01)00174-3

Rey, P. F., Fountain, D. M., \& Clement, W. P. (1994). P wave velocity across a noncoaxial ductile shear zone and its associated strain gradient: Consequences for upper crustal reflectivity. Journal of Geophysical Research, 99(B3), 4533-4548. https://doi.org/10.1029/ 93JB03105

Rey, P. F., Teyssier, C., \& Whitney, D. L. (2009a). Extension rates, crustal melting, and core complex dynamics. Geology, 37(5), 391-394. https://doi.org/10.1130/G25460A.1

Rey, P. F., Teyssier, C., \& Whitney, D. L. (2009b). The role of partial melting and extensional strain rates in the development of metamorphic core complexes. Tectonophysics, 477(3-4), 135-144. https://doi.org/10.1016/j.tecto.2009.03.010

Rudnick, R. L., \& Fountain, D. M. (1995). Nature and composition of the continental crust: A lower crustal perspective. Reviews of Geophysics, 33(3), 267-309. https://doi.org/10.1029/95RG01302

Sabra, K. G., Gerstoft, P., Roux, P., Kuperman, W. A., \& Fehler, M. C. (2005). Extracting time-domain Green's function estimates from ambient seismic noise. Geophysical Research Letters, 32, L03310. https://doi.org/10.1029/2004GL021862

Schellart, W. P., Stegman, D. R., Farrington, R. J., Freeman, J., \& Moresi, L. (2010). Cenozoic tectonics of western North America controlled by evolving width of Farallon slab. Science, 329(5989), 316-319. https://doi.org/10.1126/science.1190366

Schmandt, B., Jiang, C., \& Farrell, J. (2019). Seismic perspectives from the western US on magma reservoirs underlying large silicic calderas. Journal of Volcanology and Geothermal Research, 384, 158-178. https://doi.org/10.1016/j.jvolgeores.2019.07.015

Schmandt, B., Lin, F. C., \& Karlstrom, K. E. (2015). Distinct crustal isostasy trends east and west of the Rocky Mountain front. Geophysical Research Letters, 42, 10,290-10,298. https://doi.org/10.1002/2015gl066593

Schutt, D. L., Lowry, A. R., \& Buehler, J. S. (2018). Moho temperature and mobility of lower crust in the western United States. Geology, 46(3), 219-222. https://doi.org/10.1130/g39507.1

Seats, K. J., Lawrence, J. F., \& Prieto, G. A. (2012). Improved ambient noise correlation functions using Welch's method. Geophysical Journal International, 188(2), 513-523. https://doi.org/10.1111/j.1365-246X.2011.05263.x

Shapiro, N. M., \& Campillo, M. (2004). Emergence of broadband Rayleigh waves from correlations of the ambient seismic noise. Geophysical Research Letters, 31, L07614. https://doi.org/10.1029/2004GL019491

Shapiro, N. M., Ritzwoller, M. H., Molnar, P., \& Levin, V. (2004). Thinning and flow of Tibetan crust constrained by seismic anisotropy. Science, 305(5681), 233-236. https://doi.org/10.1126/science.1098276

Shen, W., \& Ritzwoller, M. H. (2016). Crustal and uppermost mantle structure beneath the United States. Journal of Geophysical Research: Solid Earth, 121, 4306-4342. https://doi.org/10.1002/2016JB012887

Shen, W., Ritzwoller, M. H., Schulte-Pelkum, V., \& Lin, F. C. (2013). Joint inversion of surface wave dispersion and receiver functions: A Bayesian Monte-Carlo approach. Geophysical Journal International, 192(2), 807-836. https://doi.org/10.1093/gji/ggs050

Sherrington, H. F., Zandt, G., \& Frederiksen, A. (2004). Crustal fabric in the Tibetan plateau based on waveform inversions for seismic anisotropy parameters. Journal of Geophysical Research, 109, B02313. https://doi.org/10.1029/2002JB002345

Shirzad, T., \& Shomali, Z. H. (2014). Shallow crustal radial anisotropy beneath the Tehran basin of Iran from seismic ambient noise tomography. Physics of the Earth and Planetary Interiors, 231, 16-29. https://doi.org/10.1016/j.pepi.2014.04.001

Stipp, M., \& Tullis, J. (2003). The recrystallized grain size piezometer for quartz. Geophysical Research Letters, 30(21), 2088. https://doi.org/ $10.1029 / 2003$ GL018444 
Stoerzel, A., \& Smithson, S. B. (1998). Two-dimensional travel time inversion for the crustal P and S wave velocity structure of the Ruby Mountains metamorphic core complex, NE Nevada. Journal of Geophysical Research, 103(B9), 21,121-21,143. https://doi.org/10.1029/ 98JB01494

Sullivan, W. A., \& Snoke, A. W. (2007). Comparative anatomy of core-complex development in the northeastern Great Basin, USA. Rocky Mountain Geology, 42(1), 1-29. https://doi.org/10.2113/gsrocky.42.1.1

Tatham, D. J., Lloyd, G. E., Butler, R. W. H., \& Casey, M. (2008). Amphibole and lower crustal seismic properties. Earth and Planetary Science Letters, 267(1-2), 118-128. https://doi.org/10.1016/j.epsl.2007.11.042

Tesauro, M., Kaban, M. K., Mooney, W. D., \& Cloetingh, S. (2014). NACr14: A 3D model for the crustal structure of the North American continent. Tectonophysics, 631, 65-86. https://doi.org/10.1016/j.tecto.2014.04.016

Thatcher, W., \& Pollitz, F. F. (2008). Temporal evolution of continental lithospheric strength in actively deforming regions. GSA Today, 18(4), 4. https://doi.org/10.1130/GSAT01804-5A.1

Tibuleac, I. M., \& von Seggern, D. (2012). Crust-mantle boundary reflectors in Nevada from ambient seismic noise autocorrelations. Geophysical Journal International, 189(1), 493-500. https://doi.org/10.1111/j.1365-246X.2011.05336.x

Tirel, C., Brun, J. P., \& Burov, E. (2008). Dynamics and structural development of metamorphic core complexes. Journal of Geophysical Research, 113, B04403. https://doi.org/10.1029/2005JB003694

Tsai, V. C., \& Moschetti, M. P. (2010). An explicit relationship between time-domain noise correlation and spatial autocorrelation (SPAC) results. Geophysical Journal International, 182(1), 454-460. https://doi.org/10.1111/j.1365-246x.2010.04633.x

Valasek, P. A., Snoke, A. W., Hurich, C. A., \& Smithson, S. B. (1989). Nature and origin of seismic reflection fabric, Ruby-East Humboldt metamorphic core complex, Nevada. Tectonics, 8(2), 391-415. https://doi.org/10.1029/TC008i002p00391

Wang, K., Jiang, C., Yang, Y., Schulte-Pelkum, V., \& Liu, Q. (2020). Crustal deformation in southern California constrained by radial anisotropy from ambient noise adjoint tomography. Geophysical Research Letters, 47(12), e2020GL088580. https://doi.org/10.1029/ 2020GL088580

Ward, D., Mahan, K., \& Schulte-Pelkum, V. (2012). Roles of quartz and mica in seismic anisotropy of mylonites. Geophysical Journal International, 190(2), 1123-1134. https://doi.org/10.1111/j.1365-246X.2012.05528.x

Weiss, T., Siegesmund, S., Rabbel, W., Bohlen, T., \& Pohl, M. (1999). Seismic velocities and anisotropy of the lower continental crust: A review. In Seismic exploration of the deep continental crust (pp. 97-122). Basel, Switzerland: Birkhäuser Verlag.

Wells, M. L., Snee, L. W., \& Blythe, A. E. (2000). Dating of major normal fault systems using thermochronology: An example from the Raft River detachment, Basin and Range, western United States. Journal of Geophysical Research, 105(B7), 16,303-16,327. https://doi.org/ 10.1029/2000JB900094

Wernicke, B., Axen, G. J., \& Snow, J. K. (1988). Basin and Range extensional tectonics at the latitude of Las Vegas, Nevada. Geological Society of America Bulletin, 100(11), 1738-1757. https://doi.org/10.1130/0016-7606(1988)100\%3C1738:BARETA\%3E2.3.CO;2

Wernicke, B., \& Snow, J. K. (1998). Cenozoic tectonism in the central Basin and Range: Motion of the Sierran-Great Valley block. International Geology Review, 40(5), 403-410. https://doi.org/10.1080/00206819809465217

Whitney, D. L., Teyssier, C., Rey, P., \& Buck, W. R. (2013). Continental and oceanic core complexes. Geological Society of America Bulletin, 125(3-4), 273-298. https://doi.org/10.1130/B30754.1

Whittington, A. G., Hofmeister, A. M., \& Nabelek, P. I. (2009). Temperature-dependent thermal diffusivity of the Earth's crust and implications for magmatism. Nature, 458(7236), 319-321. https://doi.org/10.1038/nature07818

Wu, G., \& Lavier, L. L. (2016). The effects of lower crustal strength and preexisting midcrustal shear zones on the formation of continental core complexes and low-angle normal faults. Tectonics, 35, 2195-2214. https://doi.org/10.1002/2016TC004245

Wu, G., Lavier, L. L., \& Choi, E. (2015). Modes of continental extension in a crustal wedge. Earth and Planetary Science Letters, $421,89-97$. https://doi.org/10.1016/j.epsl.2015.04.005

Xie, J., Ritzwoller, M. H., Brownlee, S. J., \& Hacker, B. R. (2015). Inferring the oriented elastic tensor from surface wave observations: Preliminary application across the western United States. Geophysical Journal International, 201(2), 996-1021. https://doi.org/10.1093/ gji/ggv054

Xie, J., Ritzwoller, M. H., Shen, W., \& Wang, W. (2017). Crustal anisotropy across Eastern Tibet and surroundings modeled as a depth-dependent tilted hexagonally symmetric medium. Geophysical Journal International, 209(1), 466-491. https://doi.org/10.1093/gji/ ggx004

Xie, J., Ritzwoller, M. H., Shen, W., Yang, Y., Zheng, Y., \& Zhou, L. (2013). Crustal radial anisotropy across eastern Tibet and the western Yangtze craton. Journal of Geophysical Research: Solid Earth, 118, 4226-4252. https://doi.org/10.1002/jgrb.50296

Yuan, H., French, S., Cupillard, P., \& Romanowicz, B. (2014). Lithospheric expression of geological units in central and eastern North America from full waveform tomography. Earth and Planetary Science Letters, 402, 176-186. https://doi.org/10.1016/j.epsl.2013.11.057

Zandt, G., Myers, S. C., \& Wallace, T. C. (1995). Crust and mantle structure across the Basin and Range-Colorado plateau boundary at $37 \mathrm{~N}$ latitude and implications for Cenozoic extensional mechanism. Journal of Geophysical Research, 100, 10,529-10,548. https://doi.org/ 10.1029/94JB03063

Zhu, H., Komatitsch, D., \& Tromp, J. (2017). Radial anisotropy of the North American upper mantle based on adjoint tomography with USArray. Geophysical Journal International, 211(1), 349-377. https://doi.org/10.1093/gji/ggx305

\section{Erratum}

In the originally published version of this article, the in-text citations and reference to Wang et al. (2018) included the incorrect publication year, which should be 2020. The reference and in-text citations have since been corrected, and this version may be considered the authoritative version of record. 